\title{
PROMOCIÓN DE UN DESTINO TURÍSTICO A TRAVÉS DE LAS REDES SOCIALES: \\ EL CASO DE A CORUÑA EN FACEBOOK
}

\author{
Eva Sánchez Amboage ${ }^{1}$ \\ Universidad de A Coruña \\ eva.amboaxe@gmail.com
}

https://doi.org/10.17979/redma.2010.01.05.4712

Material autorizado para su primera publicación en la revista académica Redmarka.

\section{RESUMEN:}

Tal como en la década de los 90 comentaba Nicholas Negroponte, en su obra El Mundo Digital, la tecnología, unida a la ciencia, han producido en los últimos decenios un cambio claramente perceptible en nuestra forma de vivir y de entender la realidad.

El mundo real en el que vivimos va abriendo camino a un nuevo y atractivo mundo virtual y digital que se adapta rápidamente, a las necesidades de la sociedad. Tanto es así, que hoy en día tener un perfil en internet, hablar o intercambiar fotografías a través de la red son acciones totalmente comunes y cotidianas.

Las redes sociales virtuales han realizado una progresión sorprendente y lo que en un principio parecía un lugar solo para relaciones personales se ha ido extendiendo por otros campos hasta llegar al comercial. De pronto redes sociales virtuales como Facebook, Tuenti, MySpace, etc. se convierten en grandes y accesibles portales de publicidad y promoción de distintos productos.

\footnotetext{
${ }^{1}$ Diplomada en Turismo por la Universidad de A Coruña. Máster Oficial en Dirección y Planificación del Turismo por la Universidad de A Coruña.
} 
Entre estos, el turismo también tiene su lugar. El presente trabajo pretende demostrar este hecho, a través del análisis de la presencia de una ciudad como A Coruña en Facebook.

Palabras clave: Destinos turísticos, promoción, redes sociales, Facebook.

\begin{abstract}
TOURISM PROMOTION THROUGH SOCIAL NETWORKING: THE CASE OF CORUÑA IN FACEBOOK
\end{abstract}

As in the 90s said Nicholas Negroponte, in his book The Digital World, technology, allied to science, have occurred in recent decades clearly perceptible change in the way we live and understand reality.

Nowadays, the real world we live in is rapidly giving way to an exciting new virtual world that fits to the needs of the general public.

So much so that today is common for everyone to have a profile on the internet, talk or exchange pictures over the network. In recent years they evolved from a place for exchange of personal information to arenas where publicity and other commercial uses can happen in a secure, fast, and broad way. For example, suddenly virtual social networks like Facebook, Tuenti, MySpace, etc. became large and accessible websites for advertising and promotion purposes. Tourism also has its place there and this exploratory study seeks to demonstrate this fact by analyzing the perception of a city like A Coruña on Facebook.

Keywords: Destinations, promotion, social networks, Facebook. 


\section{1- Introducción}

La conexión entre personas es una acción habitual que se repite en la mayoría de los humanos. Existen personas que pertenecen a multitud de redes, en cambio otras, les basta con pertenecer a una o a dos. En cualquier lugar y en cualquier momento alguien puede empezar o continuar una red. Cuando nacemos nuestra familia es nuestra red principal, que a lo largo del tiempo va cambiando o aumentando. Más de uno se sorprendería al descubrir como las redes afectan al individuo o como el individuo afecta a la red. Por poner un ejemplo del asombroso poder de las conexiones apuntamos un comentario que hacen Christakis y Fowler en su libro Conectados:

“...Descubrimos que si el amigo del amigo del amigo de un amigo tuyo aumenta de peso, tú aumentas de peso. Descubrimos además que si el amigo del amigo del amigo de un amigo tuyo empieza a ser feliz, tú empiezas a ser feliz... (Christakis, N. Flowler, J. 2010)".

En muchas ocasiones la felicidad, el éxito, la popularidad, etc. de una persona depende del sitio que ésta ocupe dentro de la red, aunque en muchas ocasiones no sepa distinguir cual es.

Hoy en día podemos sumar nuevas formas de comunicación y conexión de personas, entre las más recientes y con mayor repercusión encontramos las redes sociales virtuales. Se abre con ellas una red paralela a la real que, gracias al avance de la tecnología, permite a la sociedad en general infinidad de oportunidades de relación.

Las redes sociales virtuales son uno de los fenómenos de mayor crecimiento en internet debido a los servicios, principalmente de comunicación, que ofrecen. Gracias a la gratuidad de estos medios de comunicación y a las herramientas de diversión que aportan como pueden ser: juegos, subir fotografías, visualizar información de los amigos, entablar conversaciones y 
amistades o conservar relaciones de la vida real, etc. consiguen que miles de personas se conecten cada día a algunas de estas redes sociales virtuales.

Este tipo de redes se presentan como un medio idóneo para: el negocio, la publicidad, la comunicación, la captación y mantenimiento de clientes...

Entre otros sectores, el turismo, va introduciéndose en este tipo de medios con el propósito de ampliar las vías de acceso al cliente.

\section{La web 2.0 como plataforma}

La aparición de la Web 2.0 viene promovida por el desarrollo de las nuevas tecnologías y el cambio de mentalidad en: empresas y sociedad en general.

En los últimos años el cliente se vuelve más exigente, sabe y tiene información de lo que compra y como tal exige una calidad y un producto o servicio que se adapte a sus necesidades. Ya no sirve que la empresa o administración intente convencer de "lo bueno que es su producto" se necesita, además, que otros clientes o usuarios den su propia opinión, aconsejen y convenzan de que un producto o un servicio es apto para la compra. Pero este fenómeno no sólo aparece en la interacción entre empresa-cliente, sino también entre la sociedad o las personas en general. En unos casos la curiosidad y en otros el estar bien informado mueven a la gente hacia la Web 2.0.

Resulta difícil encontrar una definición neutral del término lo que puede ser debido a las propias características de la Web 2.0: libre autoridad, participación e interconexión entre usuarios.

Aún así, hacemos mención a la definición que aporta Pisani sobre este tipo de Web. "La Web 2.0 es por definición participativa e interactiva, su papel más importante es el que permite que los produsers generen contenidos propios. La evolución de la red hace posible que la gente se exprese, intercambie, cree, consuma, se organice. (Pisani, F. 2008)". 
Son muchos los que ya hablan de una Web 3.0, donde la 2.0 se intensifica aún más y las relaciones con los clientes y usuarios son, si cabe, más directas y personales.

\section{El Marketing relacional y las redes sociales como medio}

El Marketing Relacional es aquel que reconoce que cada consumidor tiene un "valor potencial" y por lo tanto diseña una estrategia destinada a "realizar" dicho potencial.

Para llevar a cabo el Marketing Relacional, las bases de datos, son fundamentales; estas se utilizan para:

Conocer los deseos y las necesidades de los clientes actuales y potenciales.

$>\quad$ Ofrecer el producto/servicio adecuado en el momento oportuno a través del canal que prefieran y de forma rentable.

Gracias al Marketing Relacional las empresas consiguen personalizar el trato con el cliente debido a la amplia información que la empresa posee del mismo. Además información como: teléfono, e-mail, correo, etc. le permiten a la organización estar en contacto directo con el cliente (para enviarle ofertas, información, invitaciones, regalos, etc.).

Este tipo de Marketing, con la llegada de la Web 2.0 o con herramientas como las redes sociales, intensifica su actividad gracias a las posibilidades de contacto que le ofrecen.

La primera red social, identificada como tal en una web, fue Sixdegrees.com que nace en 1997 en Estados Unidos. Esta, permitía un uso básico que poseen prácticamente todas las redes sociales actuales, crear un perfil, conectar con amigos y enviar mensajes de texto a otras personas que no pertenecían a la red de amigos. 
A partir de ahí, la progresión y desarrollo de estos medios ha crecido de forma desorbitada.

En nuestro país, gracias al estudio elaborado por el AIMC, entre 20 de Octubre y el 13 de Diciembre de 2009, donde eran encuestados 36.000 españoles a cerca de las redes sociales que utilizaba, podemos hacer las siguientes afirmaciones:

$>\quad$ De los 36000 encuestados solo 10216 (el 28.4\%) no pertenecen a ninguna red social virtual.

$>$ Como líder, en las redes sociales que utilizan los españoles, encontramos Facebook (61.7\%) seguido de Tuenti (20.8\%).

$>\quad$ La gran mayoría un 79.3 \% la utiliza para relacionarse con sus amistades, a esta utilidad le siguen otras como Hobbies o relaciones profesionales.

$>\quad$ El $43.5 \%$ de personas que realizaron la encuesta, ha entrado en sus redes sociales el día anterior.

$>\quad$ Sorprende el porcentaje (22.9\%) de los que nunca han vuelto a entrar (tras la apertura de su perfil en la red) o de los que hace más de un año que no entran en la red social. Esto puede ser debido a la "novedad" de este tipo de redes.

Como hemos visto Facebook, es la red social con mayor número de usuarios a nivel español y mundial.

El propio Facebook se define como "un servicio social que conecta a la gente con amigos y otros que trabajan estudian y viven cerca".

Facebook nace en 2004, de la mano de Zuckerberg, un estudiante de la Universidad de Harvard que por aquel entonces tenía 23 años. Zuckerberg analizando a sus compañeros estudiantes comprobó que empleaban mucho tiempo conectados a internet, por ello se le ocurrió reproducir online el álbum de fotos de alumnos de la facultad para facilitar el contacto entre ellos. De ahí nace Facebook (Libro de Caras), una red social en la que los universitarios de 
Harvard subían fotografías y establecían conexiones. Con el tiempo la red se amplía, se mejora y se expande por el resto del mundo. En un principio Facebook era una red, sólo para universitarios, pero tras el éxito comprobado, se abre para permitir el acceso al público en general.

Así, en la actualidad, todo aquel que quiera conectarse a Facebook sólo tiene que crear un perfil con sus datos (nombre, edad, lugares de trabajo, universidades, etc.), a través de un e-mail y en la página de Facebook. Una vez dentro, se buscan los distintos conocidos o amigos por el nombre, o se intentan acceder a nuevos contactos buscando dentro de los amigos de nuestros amigos. Con tus amigos agregados puedes enviar mensajes, compartir videos, establecer un estado para cada día, jugar a los juegos que la propia red ofrece, etc.

Facebook se convierte en la red social más utilizada en todo el mundo, desbancando así a su principal competidora y hasta hace poco líder de la red social, MySpace.

Del propio Facebook extraemos la siguiente información a cerca de la red social:

> Más de 400 millones de personas son usuarios activos de esta red social. De ellos el 50\% inician sesión en Facebook todos los días.

$>\quad$ De media un usuario tienen 130 amigos, según Christakis. $\mathrm{N}$ y Fowler. J (2010) sólo 6.6 son amigos directos o con los que realmente se establece relación. Para descifrar este dato los escritores han desarrollado el método de "la foto del amigo", basado en las fotografías que la gente publica en su página de Facebook. La idea es que dos personas que publican y etiquetan fotos el uno del otro probablemente estén más cerca socialmente que aquellas que no lo hacen.

La gente gasta más de 500 mil millones de minutos al mes en Facebook. 
$>\quad$ En lo referente a la actividad en Facebook, el usuario medio se conecta a 60 páginas, grupos y eventos.

$>$ Existen más de 70 traducciones disponibles en el sitio (la mayoría de ellas fueron realizadas por los propios usuarios de la red social con más de 300.000 usuarios de ayuda).

$>\quad$ Facebook, que en un principio era una red únicamente estadounidense, en la actualidad alrededor del $70 \%$ de sus usuarios se encuentran fuera de los Estados Unidos.

$>\quad$ La red cuenta con más de un millón de desarrolladores y empresarios de más de 180 países.

> Cada mes, más del $70 \%$ de los usuarios de Facebook se compromete con las aplicaciones de plataforma de la red.

> Más de 550.000 aplicaciones activas actualmente en la plataforma de Facebook.

$>\quad$ Más de un millón de sitios web se han integrado en la plataforma de Facebook.

> Hay más de 100 millones de usuarios activos en la actualidad, con acceso a Facebook a través de sus dispositivos móviles. Precisamente estos usuarios son dos veces más activos en Facebook que los usuarios no móviles.

Facebook no se salva de ser cuestionada por la sociedad por sus problemas de seguridad y privacidad. En la red hemos encontrado multitud de artículos que hacen referencia a este tema, incluso un "quitafacebookday" (plataforma donde se estipulaba un día: 31 de mayo de 2010 para que todo el mundo borrara su perfil como protesta a la falta de seguridad y privacidad) que muestra la negativa de muchos hacia la red.

Todo el mundo coincide al decir que, en sus inicios Facebook, era una red con unas medidas de privacidad mucho más severas que las actuales. Aunque existe una política y unas bases de privacidad que Facebook muestra, los usuarios parece no enterarse y no aceptar las medidas que la red propone y al final aparecen los problemas de suplantación de identidad, problemas de privacidad (todo el mundo puede ver tus fotos, tus amigos, etc.). En la 
actualidad Facebook intenta mejorar sus errores y al crear el perfil informa de las opciones de privacidad.

\section{El Turismo 2.0}

Al igual que para otros sectores, en el sector del turismo, la evolución de las nuevas tecnologías ha cambiado la forma de actuar de las empresas. La evolución y exigencia de los clientes obligan al sector a adaptarse a internet y a la Web 2.0. Así, el cliente tiene capacidad para determinar la reputación de las empresas gracias a sus comentarios, sus consejos, recomendaciones a otros usuarios, etc.

Podemos hablar de la creación de una nueva forma de viajar, gracias a la Web 2.0 y las redes sociales. En la planificación del viaje los protagonistas buscan información en comentarios de otros viajeros que han estado previamente en ese destino, hotel, restaurante, etc., y tras haber consumido el servicio estos se convierten en nuevos comentaristas que sirven de consejeros para otros futuros viajeros.

Así comentaba Jimmy Pons director de proyectos de Hosteltur Innova, en la tertulia de Hosteltur del 01/07/2010. Además en esta misma tertulia se hacía hincapié en que las empresas turísticas no debían de tener miedo a exponerse en la Web 2.0, sino que debían afrontar las críticas (en caso de que las hubiera) y sobre todo ser transparentes y trabajar al máximo para evitar comentarios negativos.

Navegando en la red encontramos, que todo lo que anteriormente hemos mencionado, es conocido como "Travel 2.0" o lo que es lo mismo "Viajar 2.0" o incluso "Turismo 2.0". Tras conocer el término nos hemos dedicado a recoger información sobre el Travel 2.0. Para ello hemos realizado una clasificación de las distintas páginas Web según su contenido, para intentar poner un orden al Travel 2.0. 


\author{
Páginas de planificación de viajes \\ Páginas de mapas y direcciones \\ Páginas de audio y vídeo \\ Blogs \\ Páginas especializadas en turismo \\ Empresas turísticas como perfiles de una red social
}

Por otro lado, siguiendo en la red social Facebook encontramos multitud de páginas que tienen contenido turístico. En este caso la mayoría son creadas por ayuntamientos u otras administraciones o por particulares que colocan información sobre distintos pueblos, ciudades, etc. Así, colocando la palabra "Turismo" en la barra de búsqueda de Facebook encontramos páginas como: Turismo Cangas, Ferrol turismo, Asociación Turismo Ouro Verde, Turismo Costa da morte, etc.

Como vemos todos estos tipos de páginas, que de alguna forma u otra son redes sociales e incluyen interactividad entre sus usuarios, ayudan a promocionar un destino, sea de forma positiva o negativa y a crear una imagen del destino, hotel, restaurante, etc. en la mente del consumidor, se utiliza así las tres herramientas de las hablábamos al principio: web 2.0, redes sociales y marketing relacional.

Por lo general los empresarios que deciden realizar un perfil de su empresa dentro de una red social, lo hacen para incrementar las ventas, para que sus clientes estén mejor informados o para posicionar de alguna forma la organización en la mente del consumidor. Pero, en muchas ocasiones introducirse en la web 2.0 ha desprestigiado el negocio. Este es el principal problema que encuentran los empresarios. En muchas ocasiones los clientes son demasiado sinceros, transparentes y en algunos casos mentirosos. Como sabemos, en el mundo real, las críticas se esparcen mucho antes que las buenas opiniones y esto en la red social virtual se incrementa, aún más.

\title{
5. Metodología y objetivos
}


Tras elaborar un estudio exhaustivo de la literatura en torno a las redes sociales virtuales, detectamos la ausencia de cualquier investigación que analizara el impacto que puede tener para una ciudad aparecer en Facebook o en cualquier otra red social, es por ello que surge el interés por realizar el presente estudio. Trataremos así, de averiguar cuál es la presencia de A Coruña en Facebook, e intentaremos aportar una aproximación del lugar que ocupa el turismo en esta red.

Para ello hemos realizado un estudio de las páginas de Facebook que contienen el nombre Coruña. Al realizarla automáticamente aparecen 500 resultados, es decir 500 páginas que contienen el nombre de la ciudad. Nuestra sorpresa aparece cuando a partir de la página 37 descubrimos que las siguientes, hasta la 500 estaban en creación, es decir, simplemente aparece el nombre de la página pero no tienen información en su interior. Esto según nuestra opinión, puede deberse a dos motivos: abrir las páginas para guardar el dominio en Facebook y en un futuro crearla, o simplemente personas que crean el perfil en Facebook, por considerarlo novedoso y que posteriormente no lo vuelven a utilizar. Consideramos que el primer motivo es más evidente si tenemos en cuenta que la mayoría son páginas de empresas, colegios, facultades, etc.

Esta situación hizo replantearnos de nuevo el estudio, y buscar distintas alternativas. Finalmente decidimos analizar cuatro ciudades más (por el motivo de que en todas se repite el mismo caso que el de A Coruña), para completar el trabajo y finalmente poder hacer una comparación entre las conclusiones de cada ciudad, y saber, más detalladamente cuál es la situación de A Coruña en Facebook.

Además, ese elevado número de páginas en creación nos ofrece las siguientes garantías: por un lado el interés del público en general por las redes sociales y por otro el carácter novedoso de este tipo de redes y por lo tanto del presente trabajo. 
Las ciudades elegidas para analizar, junto con A Coruña, han sido: Gijón, Santander, San Sebastián y Vigo, puesto que consideramos que poseen unas características comunes con Coruña, que permiten una comparación clara y efectiva de los resultados. Dichas características son las siguientes:

$\checkmark \quad$ La situación geográfica: Todas son ciudades costeras. Vigo, que se ha elegido principalmente para establecer una comparativa con otra ciudad gallega, es la ciudad que posee mayor rivalidad con A Coruña y con la que comparte las aguas del Atlántico. El resto de ciudades aunque se sitúan en. la cornisa Cantábrica, en conjunto, todas pertenecen al norte de la Península Ibérica, lo que nos ofrece otras características comunes.

$\checkmark \quad$ Clima: Al igual que A Coruña, y gracias a ser ciudades del Norte de España poseen un clima muy parecido, concretamente un clima oceánico templado y húmedo con temperaturas que oscilan entre los 14 y $17^{\circ}$, pudiendo incrementarse en el caso de Vigo.

$\checkmark \quad \quad$ No habitantes: Coruña: 246.056, Gijón: 277.554, Santander: 181.802, San Sebastián: 185.510 y Vigo 297.332.

$\checkmark \quad$ Playas Urbanas: En el caso Coruñés destacamos las playas de Riazor y el Orzán, en Gijón encontramos: la playa de San Lorenzo, en Santander: la playa El Sardinero, en San Sebastián: la Concha, Ondarreta y Zurriola y finalmente en Vigo apuntamos la playa de Samil. Todas ellas tienen un nexo común y este es la ubicación dentro de la propia ciudad, que proporcionan al lugar un atractivo turístico.

$\checkmark \quad$ Ciudades con puertos: Las cuatro ciudades cuentan con puertos que han sido y son relevantes para la economía de la ciudad.

$\checkmark \quad$ El último nexo común que apuntamos se encuentra en la clasificación turística "España Verde". A nivel turístico, al estar bajo el paraguas de España Verde, se confirma que ambas ciudades comparten características comunes.

¿Por qué Facebook?

En un primer momento la intención del estudio era analizar además otra importante red social y que podía aportar un gran contenido turístico a través 
de sus vídeos, como es YouTube. Finalmente por falta de tiempo, se ha decido emprender el análisis simplemente con Facebook, del cual podíamos extraer los datos suficientes para realizar la Máster-Tesis. Además el motivo principal que originó dicha elección fue la novedosa noticia de que Facebook ocupaba el primer lugar en el ranking mundial de las redes sociales, y también se situaba en este mismo lugar, en el caso español. Este dato incrementó más si cabe el interés por su análisis.

El estudio pretendía dar respuesta a los siguientes objetivos:

1. Analizar de forma general el papel que ocupa el turismo en Facebook.

2. Averiguar la presencia de Coruña en Facebook.

3. Extraer la opinión de los usuarios de Facebook acerca de A Coruña.

4. Estudiar la situación de Gijón, Santander, San Sebastián y Vigo en Facebook.

\section{Resultados}

Tras el estudio y recogida de datos de la presencia de las distintas ciudades en Facebook, llegamos a los siguientes resultados:

\section{Resultados de A Coruña}

Carácter de las páginas más utilizadas, ante la búsqueda de Coruña en Facebook.

Gráfico No1 


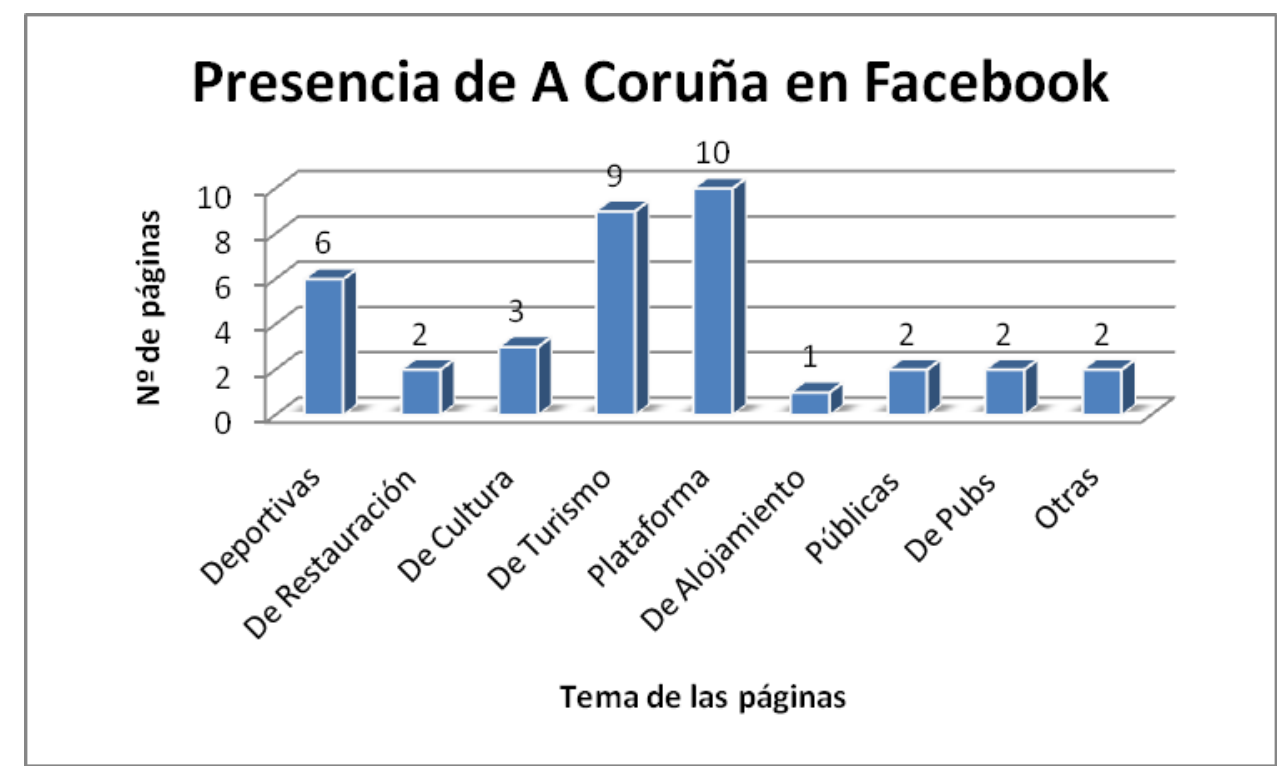

Fuente: elaboración propia

Como observamos en la imagen, la ciudad de A Coruña tiene una mayor presencia en las páginas "Plataforma" de Facebook (aquellas que buscan conseguir un elevado número de amigos, para una causa concreta). La mayoría de estas páginas que hemos denominado "plataforma" pretenden resaltar y promocionar la ciudad, como es el caso de:

$>\quad$ A Coruña sede del Mundial 2018.

> Para que La Coruña sea, de nuevo capital de Galicia.

> Dios creó La Coruña...y después el resto del mundo.

$>\quad$ La Coruña sede financiera de Galicia.

$>\quad$ Coruña de Toda la Vida (CTV).

Como vemos, aunque sólo sea por el título comprobamos que, ofrecen una imagen positiva de la ciudad, donde sobre todo, predomina un sentimiento patriota y una defensa del lugar.

Dentro de las páginas "plataforma" encontramos que dos de ellas revelan puntos negativos de A Coruña y que su contenido, puede crear una mala imagen de la misma, como son:

Yo también aparco donde me da la gana en Coruña

A mí tampoco me gusta como han dejado la calle Barcelona (A Coruña) 
En estas dos páginas se aportan fotografías tanto, de las incidencias de tráfico como de la nueva calle Barcelona. Acompañados de estas imágenes se exponen comentarios que pueden dañar (para una persona que no conozca la ciudad) la imagen del lugar, o incluso influir en la decisión de que A Coruña sea el lugar de sus vacaciones.

La última "plataforma" a destacar es "Yo también quiero que mi ciudad se llame La Coruña". Existen 2.702 personas que están a favor de que la ciudad se llame La Coruña, y la mayoría alega que éste ha sido siempre el nombre de la ciudad. También encontramos comentarios de personas que prefieren la eliminación del artículo quedando simplemente con Coruña, y algunos otros, minoritarios, que prefieren que el nombre recoja el artículo A. La mayoría de las plataformas nos informan de las opiniones y preferencias de los propios ciudadanos que podrían servir en un futuro para dirigir de una forma u otra la actividad de la ciudad.

Siguiendo con el análisis del gráfico vemos que en segunda posición, Coruña, tiene más presencia en las páginas de carácter turístico. Aquí, debemos resaltar que la mayoría de estas páginas presentan la ciudad a través de fotografías y de comentarios, (mayoritariamente a favor de la ciudad). Se crea una promoción entre los propios usuarios y se aconsejan y destacan atractivos de la ciudad a aquellos que buscan información sobre la misma, como si de una AAVV virtual se tratara.

En tercer lugar encontramos las páginas de carácter deportivo, donde el producto estrella es el Deportivo de la Coruña que arrastra a miles de aficionados. Sorprende que todas las páginas tengan un número elevado de aficionados. Aunque en estas no se habla de la ciudad, en sí, el nombre es muy reconocido.

El último tipo de páginas que queremos destacar es "Otras", y dentro de estas, la página que Ikea ha elaborado con la reciente apertura de la tienda en Coruña. En esta página, como hemos podido ver en las fichas detalladas, transmite una visión de atraso y ruralidad de Coruña y de Galicia en general. 
Finalmente apuntamos algunas conclusiones generales que extraemos del análisis:

$>\quad$ Las páginas Públicas (como puede ser la de Bibliotecas municipales) 0 de cultura ofrecen, en ocasiones, más información de otros lugares del mundo que de su propia ciudad (ej. Mejores playas del mundo, recomendar el País Vasco para la Semana Santa, destacar los mejores museos del mundo, etc.).

$>\quad$ La fiesta por excelencia, que más gusta a extranjeros y coruñeses es el San Juan.

La página del Hotel Moon, es el único hotel (de las 5 ciudades) que hace promoción de su ciudad, aportando fotografías e información.

$>$ En general, analizando los comentarios, comprobamos que las aportaciones negativas que más se repiten sobre A Coruña son: la lluvia y el mal tiempo y por otro lado las playas y su continuo relleno de arena.

$>\quad$ Aunque Coruña tenga mayor presencia en las páginas de turismo, lo cierto es que solo encontramos una AAVV en la red social.

$>\quad$ Comprobamos además, que las redes sociales son una nueva vía para que las pequeñas empresas y equipos coruñeses se den a conocer y tengan la posibilidad de promocionarse.

Número de amigos que Coruña posee según el carácter de las páginas de Facebook.

Gráfico No2 


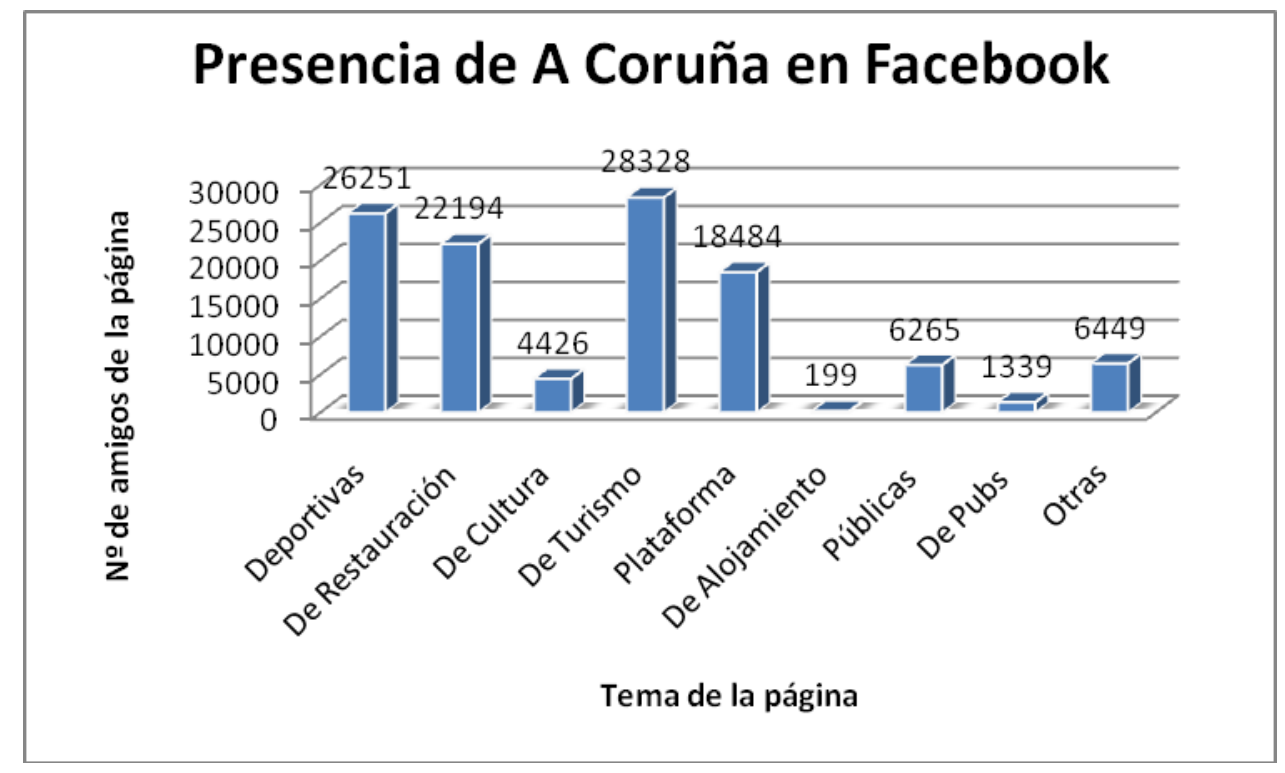

Fuente: elaboración propia

En esta gráfica se analiza la presencia de Coruña en Facebook según el número de amigos de cada página. Así, observando dicha gráfica extraemos las siguientes conclusiones:

> Las páginas con mayor número de amigos son las dedicadas al turismo, sin embargo el mayor número de páginas pertenece, como hemos visto en el gráfico anterior, a las "plataformas". Este es un dato positivo para nuestro estudio, ya que resalta la importancia e interés del contenido turístico en la red social virtual.

También encontramos, en segundo lugar, las páginas de carácter deportivo con 26.251 amigos. Este dato sorprende al compararlo con el número de páginas sobre Coruña, donde las deportivas quedaban en un tercer lugar, bastante alejadas de sus principales competidoras, por eso entendemos que las páginas deportivas tienen un número reducido pero con un elevado número de seguidores.

$>$ En el caso de las páginas de restauración, que como vemos se posicionan en tercer lugar, es destacar que 21.162 personas de las 22.194 totales, pertenecen a una sola página, y por lo tanto a un solo restaurante, La Bombilla.

Si nos fijamos en el número de amigos de las "plataformas" vemos que estas descienden a un cuarto lugar, información destacable teniendo en cuenta que se situaban en primera posición en el ranking por número de páginas. En 
este caso, y teniendo en cuenta que uno de los motivos principales de las "plataformas" es conseguir adeptos y que su causa se propague por la red, entendemos que los temas que trata, pueden no ser de interés para el público en general o su gestión no ser del todo correcta.

Tipo de páginas que recogen un mayor número de fotografías de Coruña en Facebook.

Gráfico №3

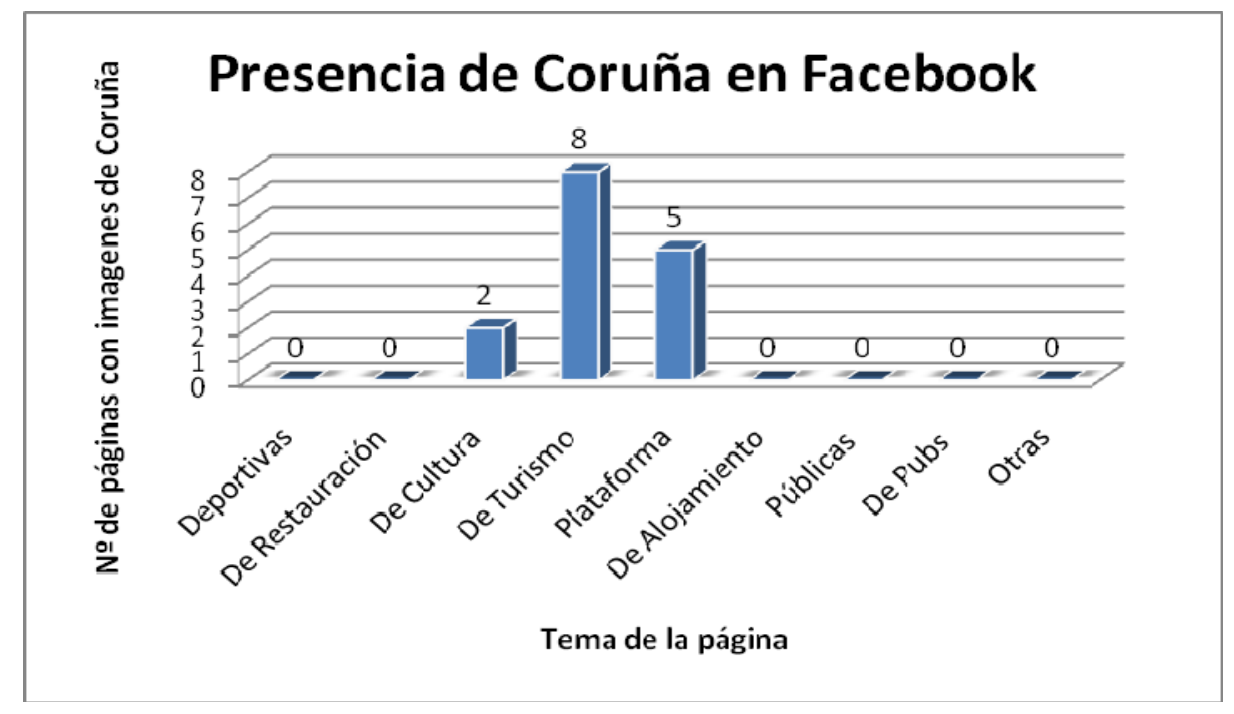

Fuente: elaboración propia

En este caso podemos observar que las páginas de turismo vuelven a situarse a la cabeza del estudio y por lo tanto son las que contienen un mayor número de fotografías de la ciudad. Este dato es muy importante para evaluar la presencia y la imagen de Coruña en Facebook, puesto que en este tipo de redes sociales las imágenes son primordiales y forman parte de la esencia del contacto virtual. Cabe aportar que la mayoría de las imágenes son por un lado fotografías aéreas de la ciudad y por otro de las playas y calles de la misma. Destaca la página Coruña Fotos con un mayor número de álbumes de la ciudad.

Como vemos, la gran mayoría de las páginas no contienen fotografías, lo que desde un punto de vista personal, consideramos perjudicial para la promoción de A Coruña en las redes sociales, puesto que en este medio las imágenes son 
fundamentales. Por ello sería interesante que todas las páginas, independientemente del tema recogieran fotografías de sus ciudades.

\section{Resultados de Gijón}

Carácter de las páginas más utilizadas, ante la búsqueda de Gijón en Facebook.

Gráfico $N^{\circ} 4$

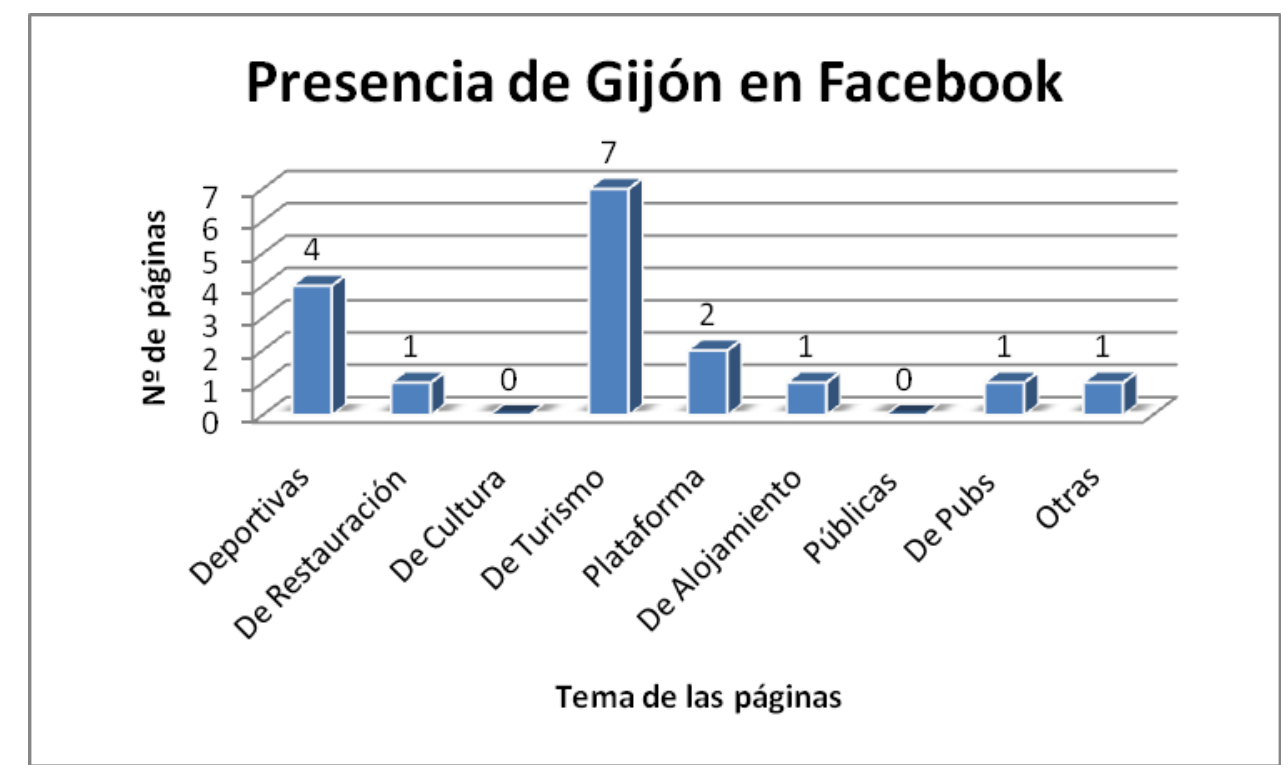

Fuente: elaboración propia

El presente gráfico nos muestra que en el caso de Gijón las páginas dedicadas a turismo son, con gran diferencia, las que más presencia tienen en la red. Además, analizando más detalladamente el caso de las páginas turísticas vemos que estas son más especializadas que en el caso de las de A Coruña. Ejemplo de sus páginas turísticas:

> Visita Gijón-Todo lo que puedes hacer en Gijón.

$>\quad$ Turismo rural en Gijón....y entorno.

$>\quad$ Gijón calidad turística.

En segunda posición encontramos las páginas deportivas, que como vemos, al igual que A Coruña, son uno de los temas que más interés tienen en la red.

En el caso de las páginas plataforma, encontramos bastante rivalidad entre el Oviedo y Gijón, a través de sus equipos de futbol.

Sorprende que no exista ninguna página de cultura ni de públicas. 
Número de amigos que Gijón posee según el carácter de las páginas de Facebook.

Gráfica No 5

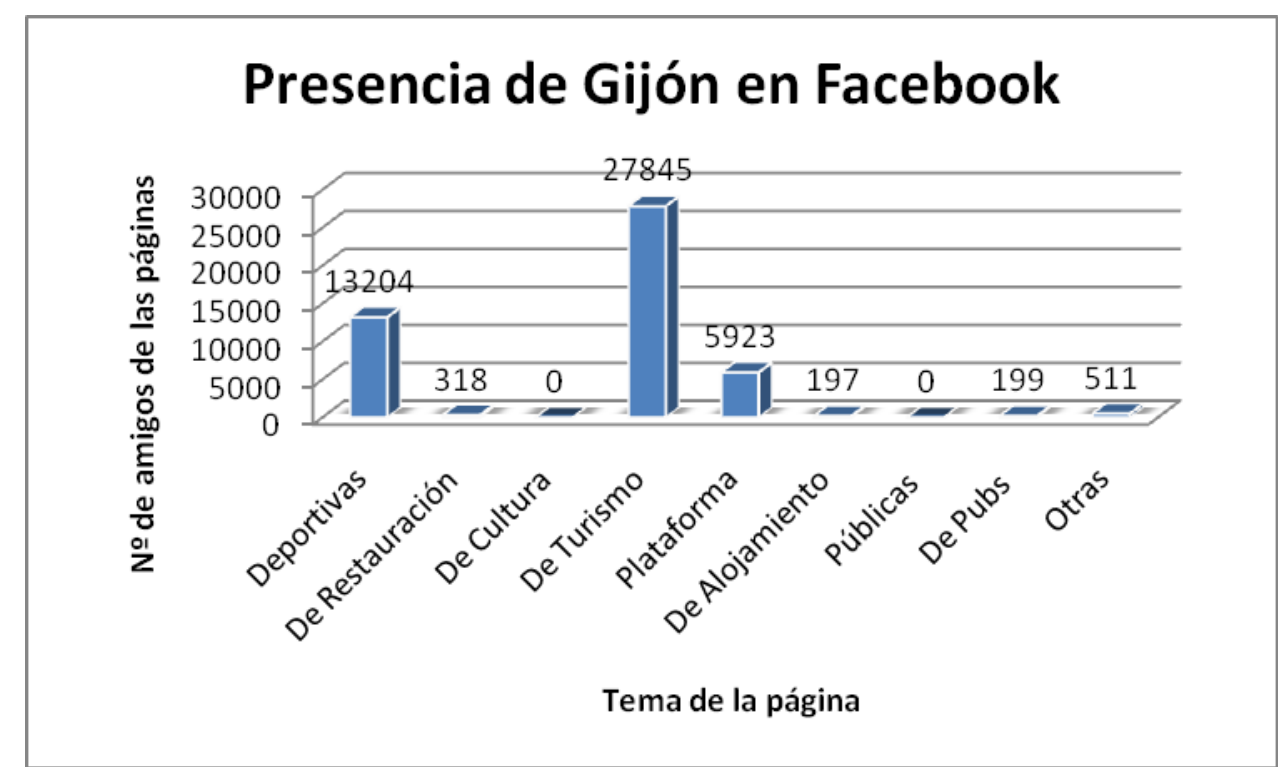

Fuente: elaboración propia

En relación al número de amigos de la página comprobamos que al igual que en el caso de A Coruña, la mayoría, se sitúan en las páginas de turismo (27845).

A este tipo de páginas le siguen las deportivas con (13204) y a estas las plataformas (5923).

Sorprende que el resto de páginas casi no posean seguidores.

La página con mayor número de amigos es "Visita Gijón-Todo lo que puedes hacer en Gijón" (17.428) con lo que volvemos a ver la importancia del turismo en Facebook.

En total, existen 48.197 personas que están relacionadas con alguna de estas páginas de Gijón. 
Tipo de páginas que recogen un mayor número de fotografías de Gijón en Facebook.

Gráfica $N^{0} 6$

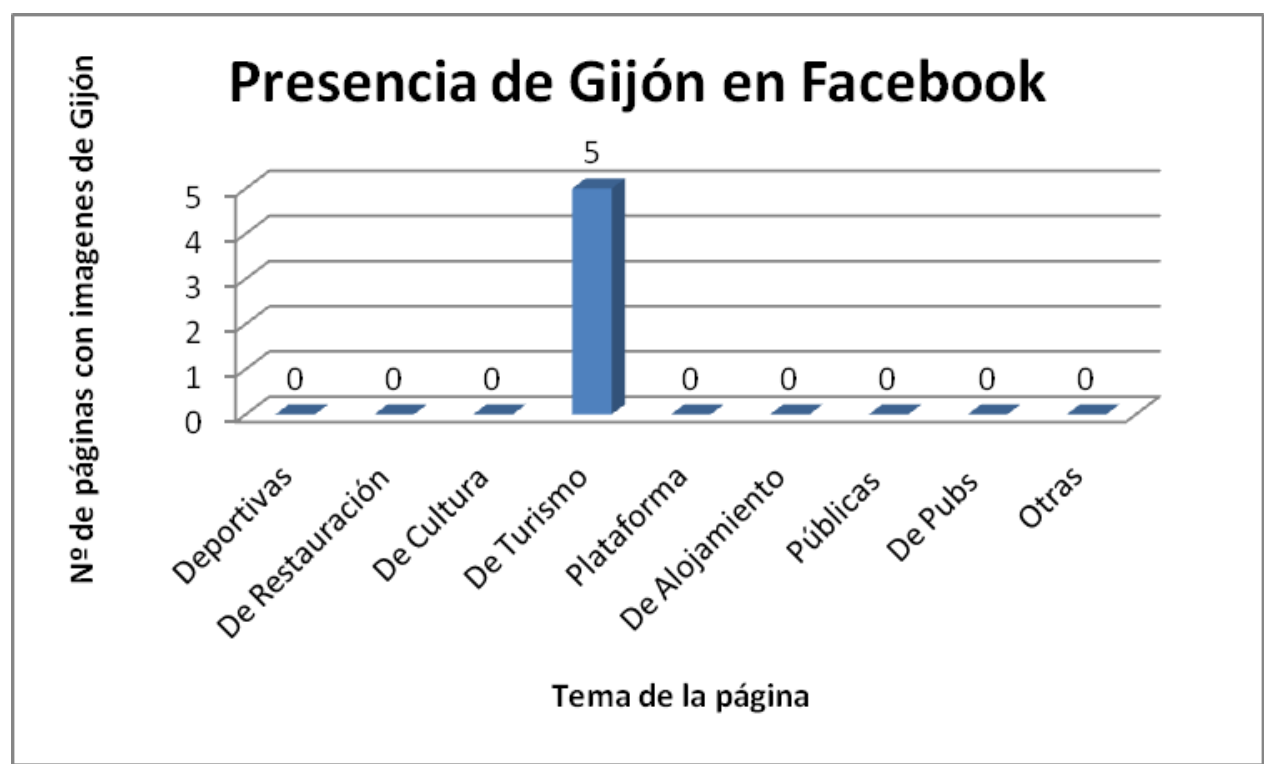

Fuente: Elaboración propia

En este gráfico podemos ver, aún de forma más clara, que el tipo de páginas que poseen un mayor número de imágenes de Gijón, son las de carácter turístico. En este caso, son las únicas páginas que recogen fotografías de la ciudad.

\section{Resultados de Santander}

Carácter de las páginas más utilizadas, ante la búsqueda de Santander en Facebook.

Gráfico No7 


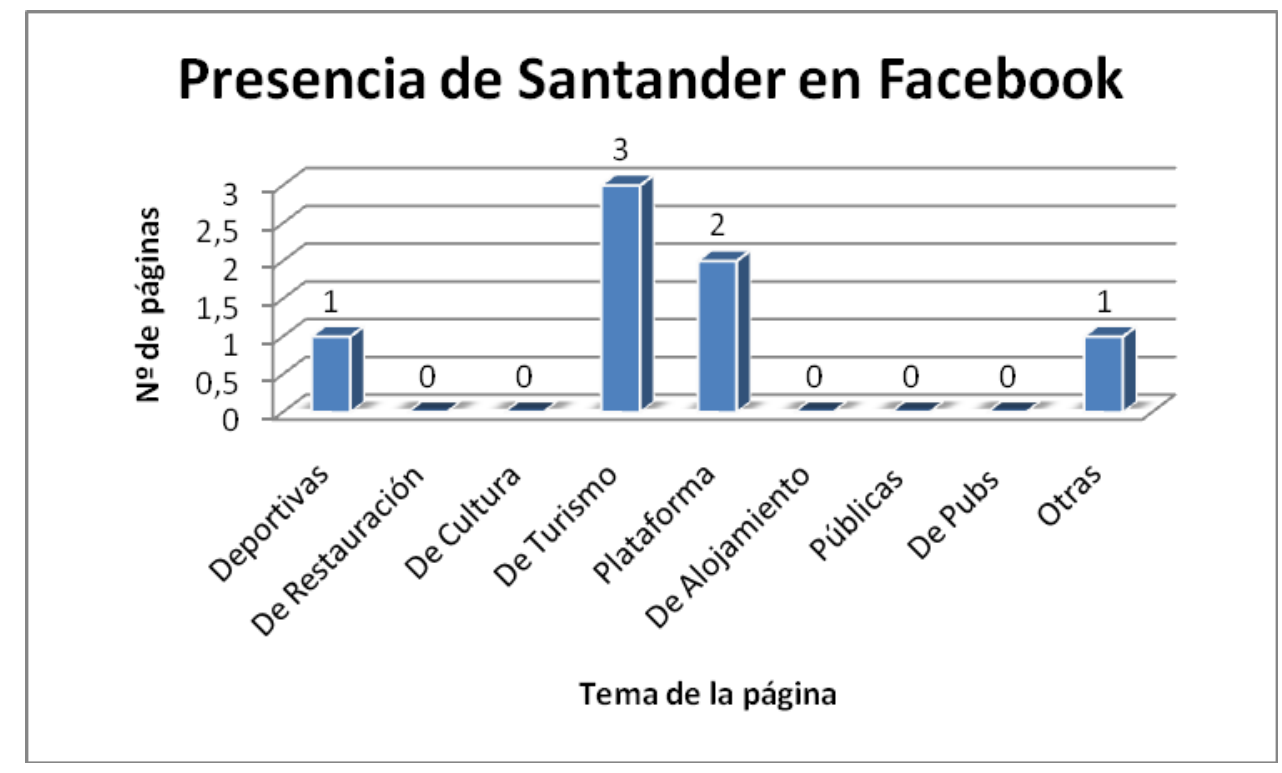

Fuente: elaboración propia

Como vemos, el turismo vuelve a ser el tema principal en cuanto a número de páginas se refiere, seguida de las "plataformas" y de las páginas de deportes. El resto de temas, como vemos no poseen páginas.

Aunque la muestra es muy pequeña, nos sorprende que existan muchos grupos que no poseen ninguna página.

Número de amigos que Santander posee según el carácter de las páginas de Facebook.

Gráfico № 8

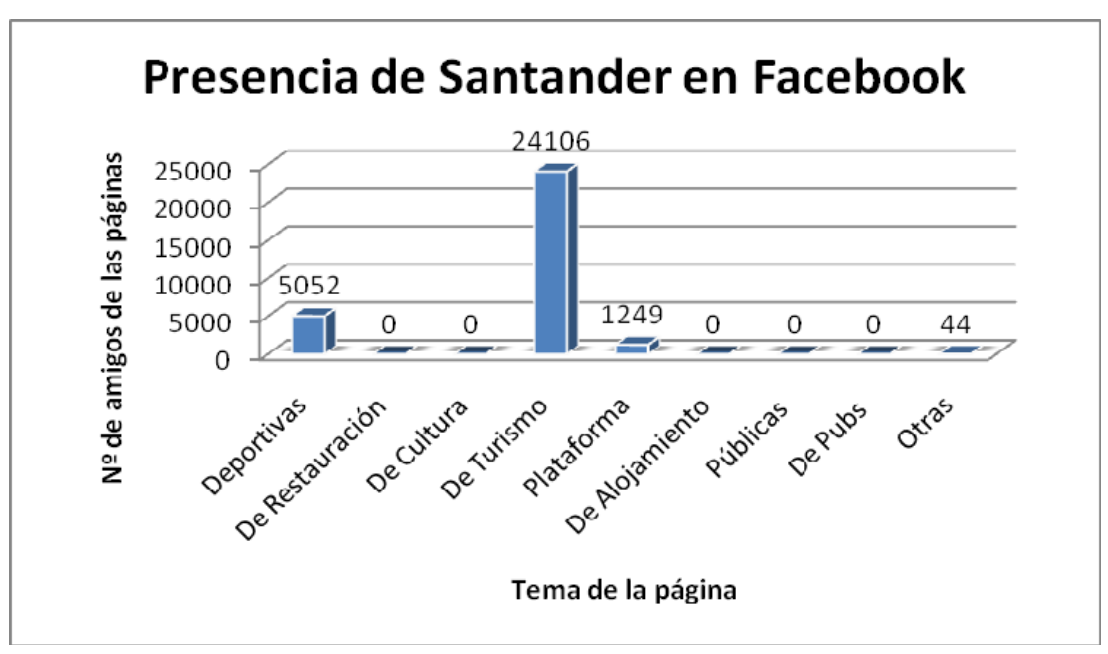


Fuente: elaboración propia

En cuanto al número de amigos, comprobamos que las páginas de turismo son las que más adeptos tienen. Aquí, debemos destacar que de las 24.106 personas que les gustan las páginas de turismo 20.030 pertenecen a una única página que se llama "Santander".

Al igual que en las dos ciudades anteriores, las páginas deportivas son una de las que más aficionados recogen, en esta caso (5052) personas.

El resto de páginas, exceptuando las plataformas (1249) casi no tienen fans.

En total Santander de España recoge 30.451 amigos.

Tipo de páginas que recogen un mayor número de fotografías de Santander en Facebook.

Gráfico No 9

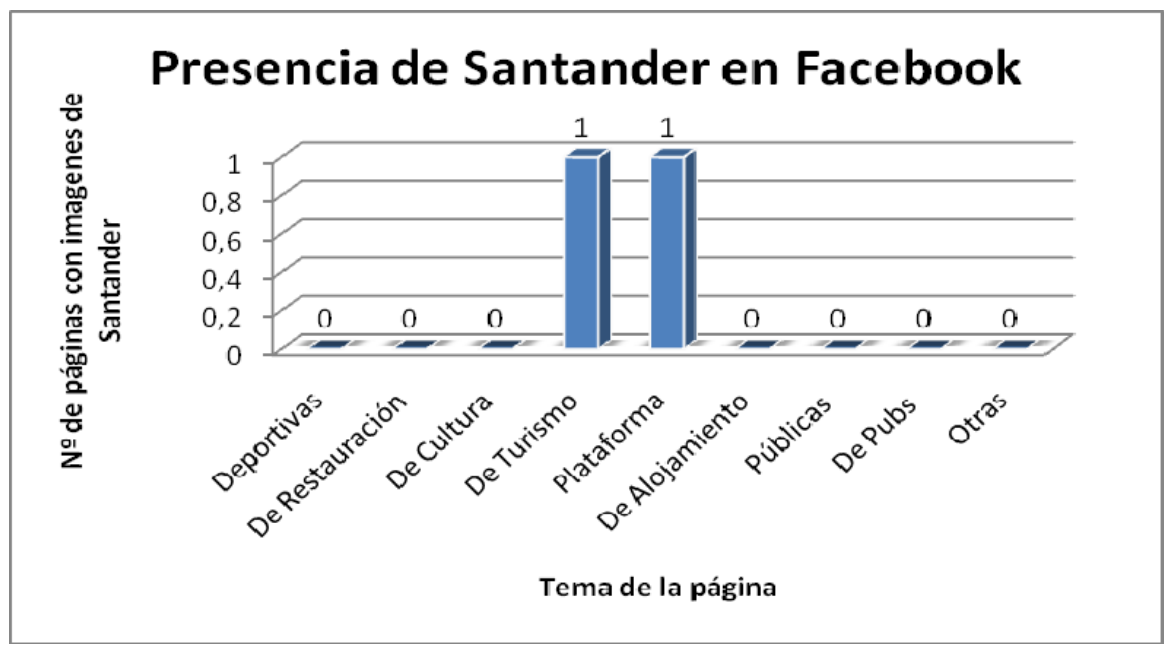

Fuente: elaboración propia

Al tener Santander un número tan limitado de muestra, provoca que los resultados también sean escasos. En esta gráfica vemos como solo dos páginas tienen fotografías de Santander, por un lado una dedicada a turismo y por el otro una página "plataforma". El resto de páginas no incluyen ninguna fotografía de su ciudad. 


\section{Resultados San Sebastián}

Carácter de las páginas más utilizadas, ante la búsqueda de San

Sebastián en Facebook.

Gráfica No 10

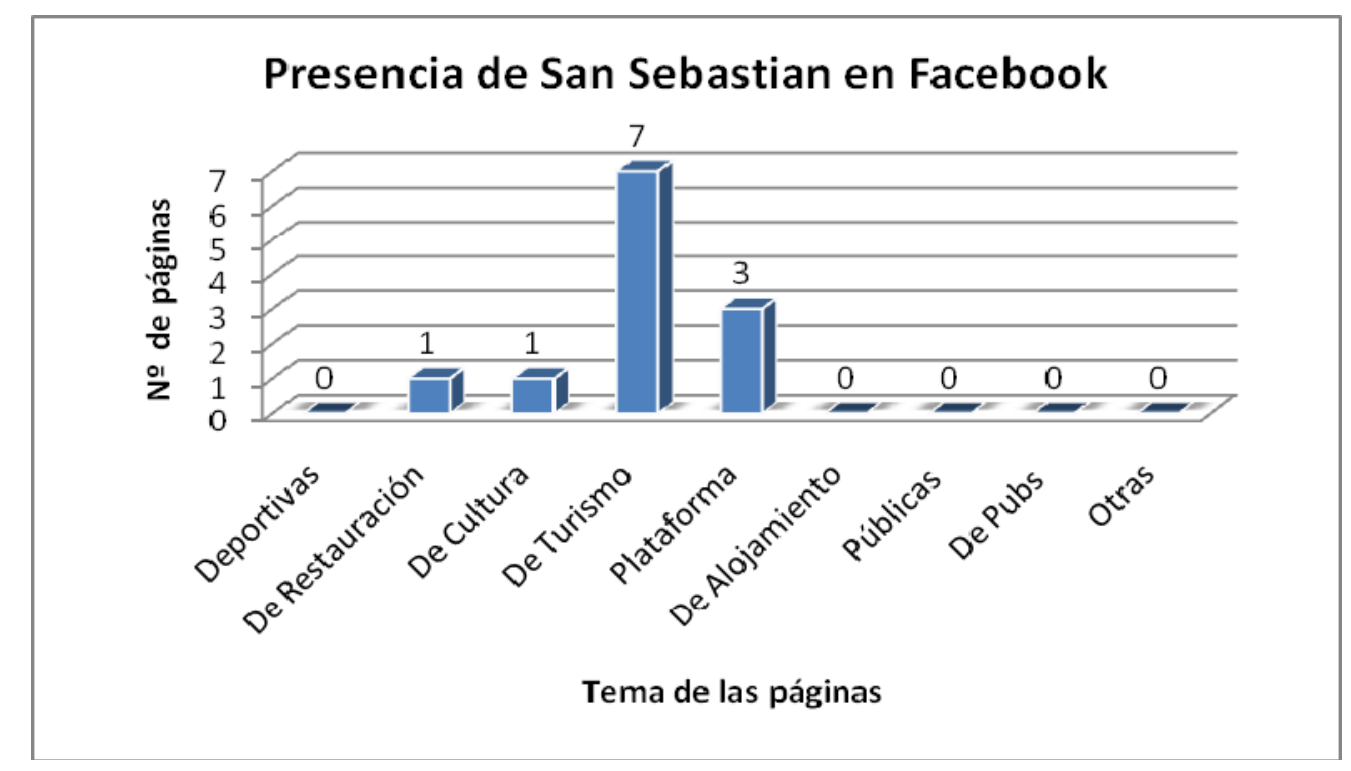

Fuente: elaboración propia

Ante la gráfica y al igual que los dos casos anteriores las páginas de turismo vuelven a ser las que tienen una mayor presencia en la red. Observamos que las páginas de turismo destacan por encima de las demás.

Encontramos, dentro de las páginas de turismo dos páginas de San Sebastián que han sido creadas por extranjeros, en un caso por un francés, y en otro por una guía inglesa. Esto aporta una imagen moderna, abierta e interactiva de la ciudad donde los turistas parecen acoger muy bien la idea.

Nos llama la atención que el grupo de temas deportivos carezca de páginas, aunque eso se deba a los equipos de las ciudades y a su afición.

Número de amigos que San Sebastián posee según el carácter de las páginas de Facebook.

Gráfico No 11 


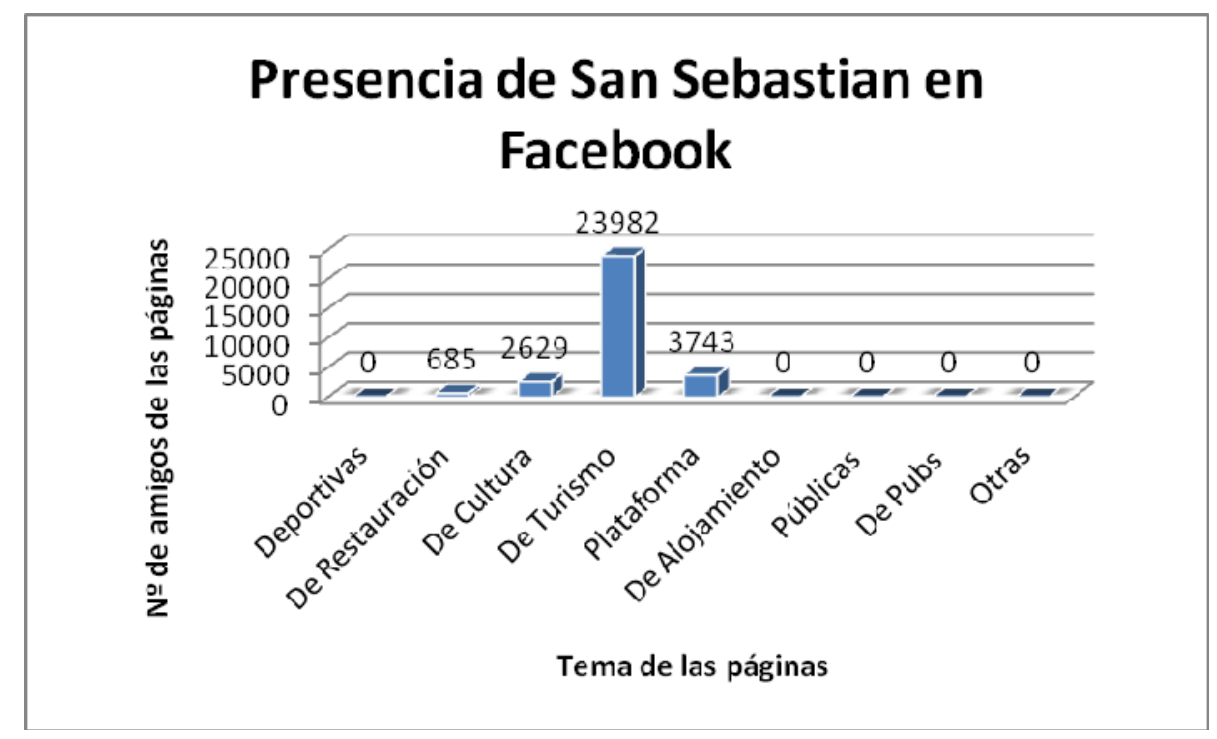

Fuente: elaboración propia

En este caso, y en consecuencia de lo apuntado en la gráfica anterior, observamos que las páginas con un mayor número de fans, vuelven a ser las turísticas (23982) por encima de cualquier otra.

En concreto, la página con mayor número de amigos responde al nombre "San Sebastián/Donostia". Esta se utiliza como foro, los que quieren visitar la ciudad piden consejo a los lugareños a través de la página.

En total San Sebastián posee 31.139 amigos.

Tipo de páginas que recogen un mayor número de fotografías de San Sebastián en Facebook

Gráfico No 12 


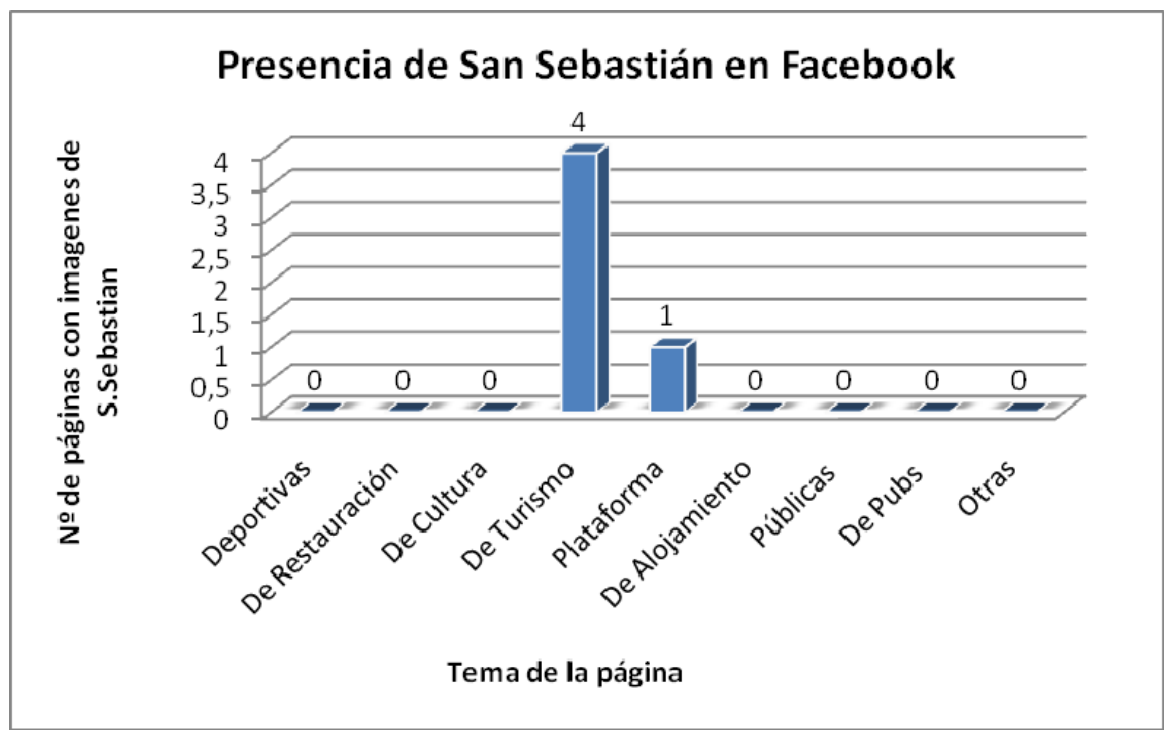

Fuente: elaboración propia

Al igual que en el resto de las ciudades analizadas las páginas de turismo son las que más imágenes aportan de San Sebastián. Solo existe otro tipo de páginas, las "plataforma" que colocan fotografías del lugar.

En este caso la misma página que hemos resaltado por número de amigos, la volvemos a destacar al estudiar el número de fotografías. "San Sebastián/Donosti" es la página que posee un mayor número de imágenes de la ciudad que reflejan todos sus atractivos.

\section{Resultados de Vigo}

Carácter de las páginas más utilizadas, ante la búsqueda de Vigo en Facebook

Gráfico No13 


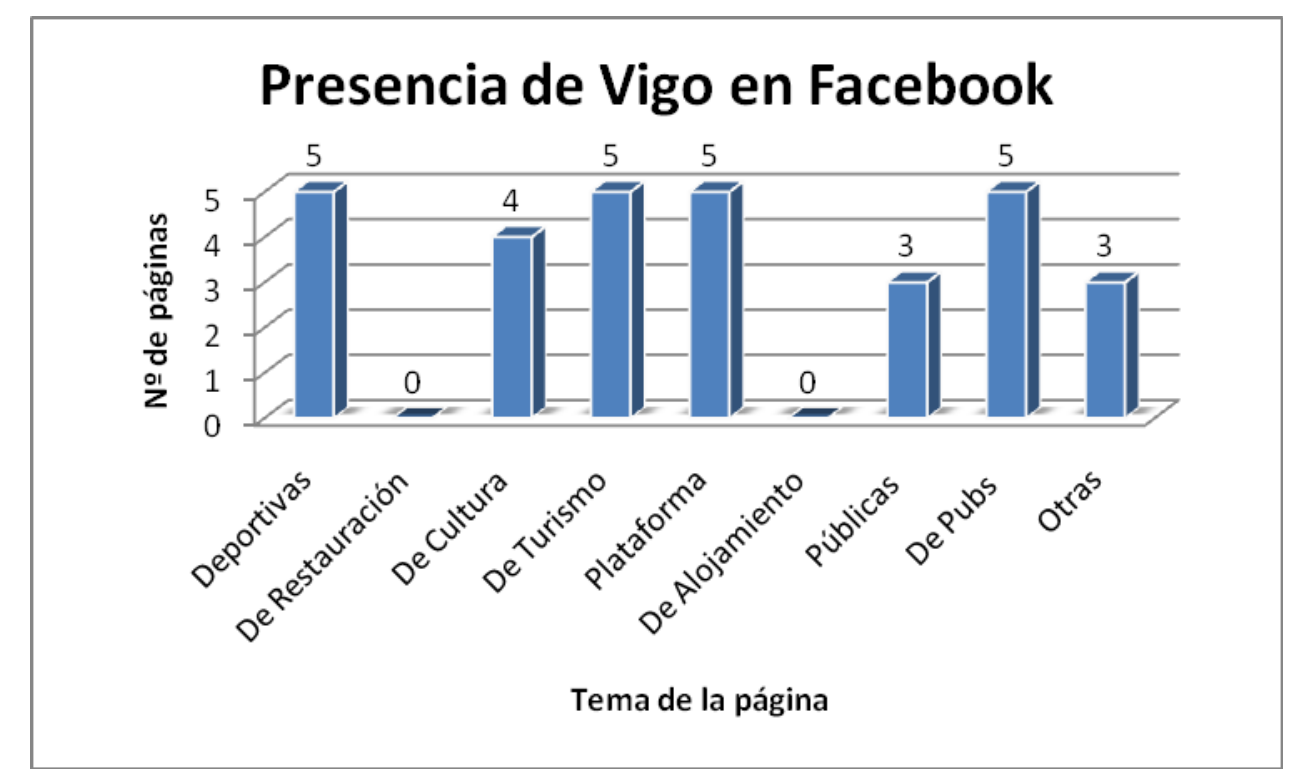

Fuente: elaboración propia

En el análisis del presente gráfico comprobamos que la situación de Vigo en Facebook es más heterogénea que en el resto de ciudades.

Observando la imagen, vemos que la ciudad de Vigo coincide en el número de páginas de varios grupos: deportivas, de turismo, plataformas y Pubs.

Sorprende principalmente el elevado número de páginas de Pubs, pero lo cierto es que Vigo es una ciudad con numerosos pubs y bares y si a eso le sumamos que los jóvenes son unos de los que más utilizan Facebook y los pubs, ya encontramos una respuesta para que esta cifra sea tan elevada.

En este análisis de las páginas debemos destacar la aparición de rivalidades entre aficionados del Deportivo y del Celta. En este caso, las páginas son elaboradas por los fans del Deportivo para desprestigiar al Celta de Vigo. Este tipo de grupos no los hemos encontrado en el caso de Coruña.

Número de amigos que Vigo posee según el carácter de las páginas de Facebook.

Gráfico No 14 


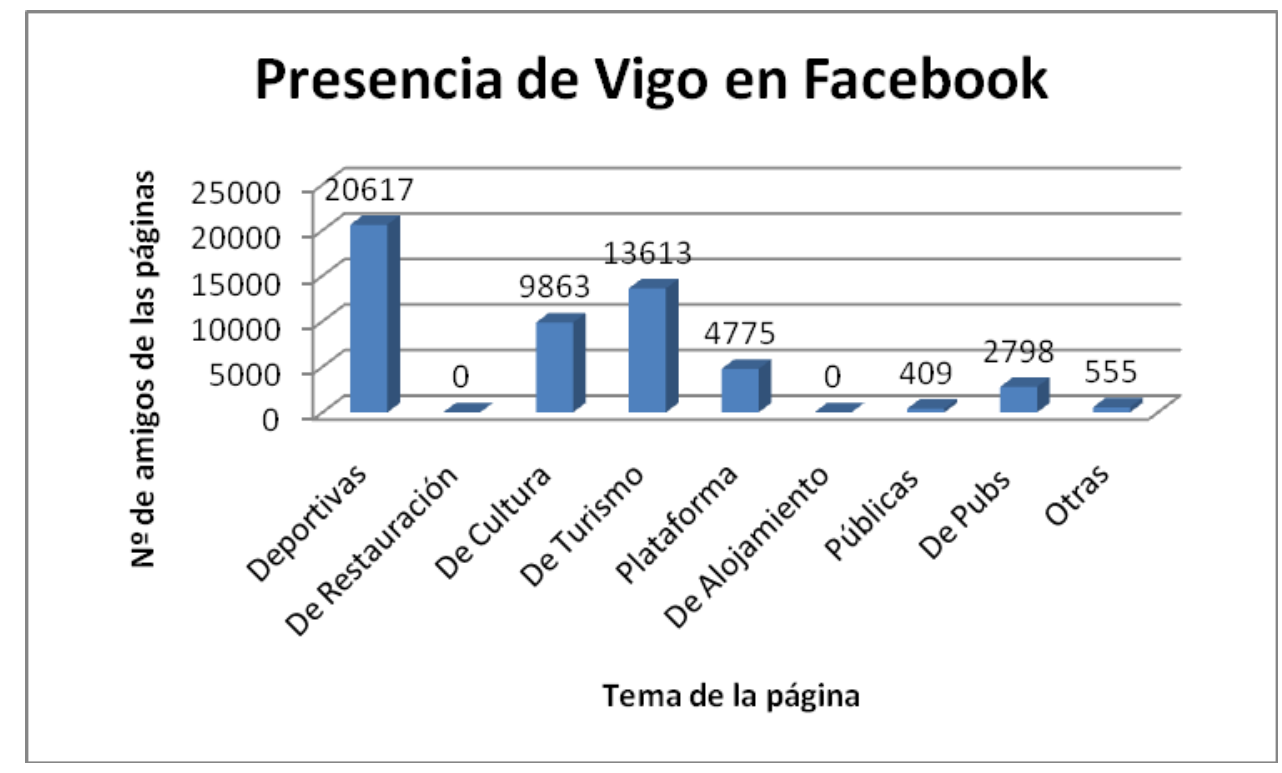

Fuente: elaboración propia

Sin embargo al analizar los datos referentes al número de amigos, vemos que las cifras cambian. En este lugar, las páginas con más fans son las deportivas, seguidas de las turísticas que en todas las ciudades anteriores eran las que más amigos poseían.

Los pubs, aún siendo los que más páginas tienen, se sitúan en un puesto muy bajo en cuanto a número de amigos.

En total Vigo recoge 52630 amigos al sumar todas sus páginas.

Tipo de páginas que recogen un mayor número de fotografías de Vigo en Facebook.

Gráfico No 15 


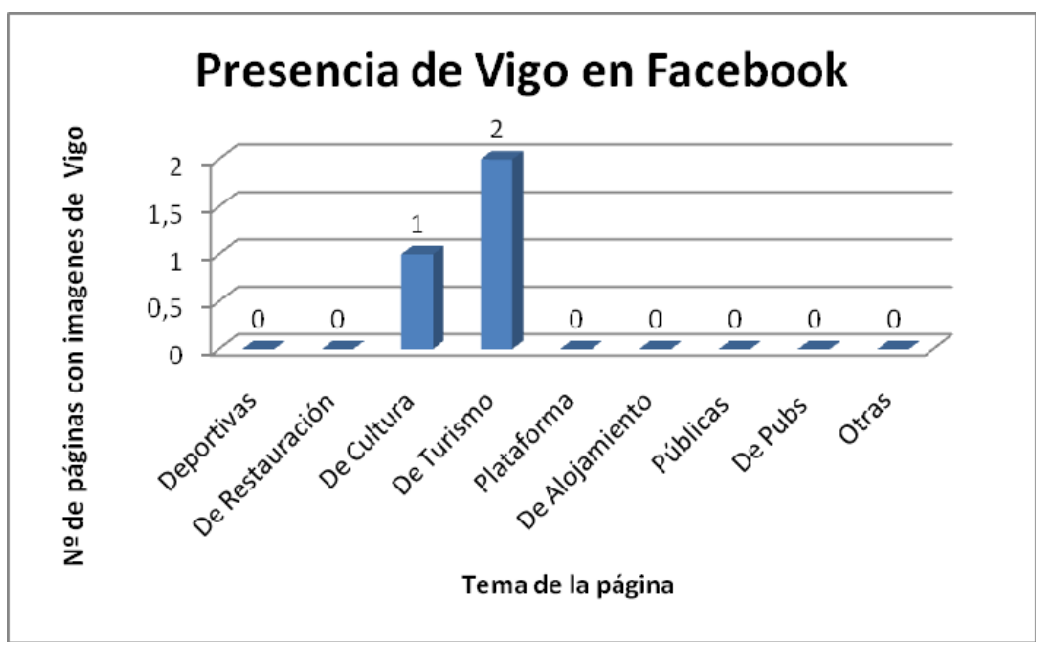

Fuente: elaboración propia

Como vemos, el turismo vuelve a recoger el mayor número de fotografías de la ciudad. Sorprende sobre todo que de las 30 páginas solamente 3 , aporten imágenes de Vigo, lo que representa un descuido en cuanto a la promoción de la ciudad.

\section{Comparación de resultados}

La comparación de los datos de todas las ciudades se ha realizado en dos gráficas. Uno que contempla simplemente el número de amigos según el carácter de las páginas y otro que incluye en la misma gráfica el número de fotografías y el número de páginas. El motivo de esta división es para evitar que los datos del número de páginas y fotografías queden ocultos por el elevado número de amigos.

Gráfico No 16 


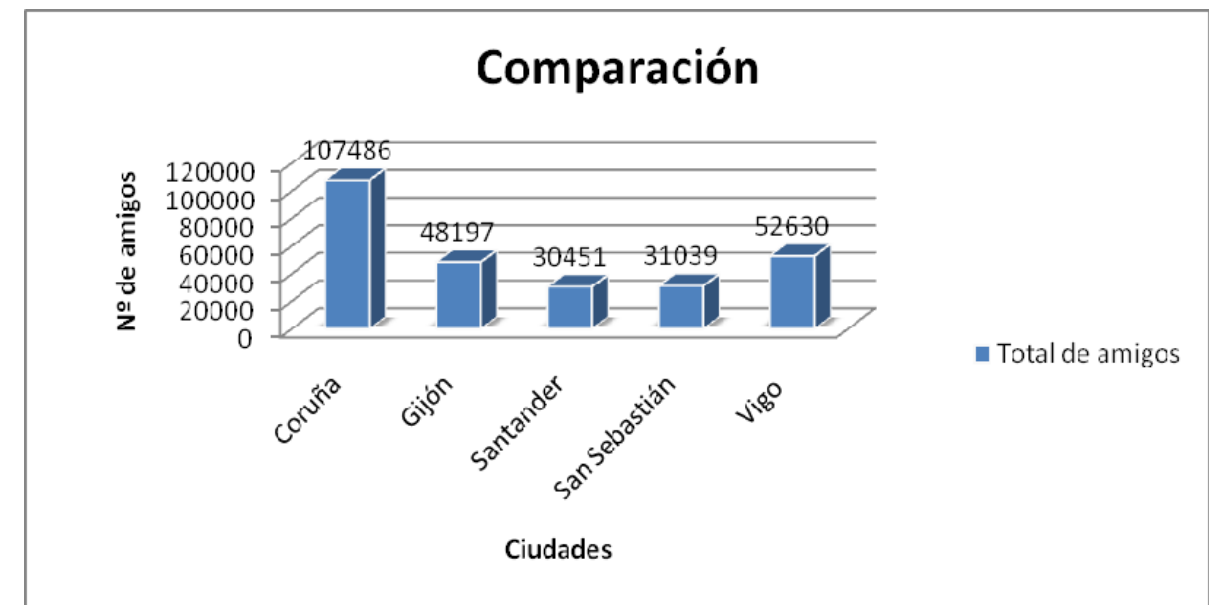

Fuente: elaboración propia

Gráfico No 17

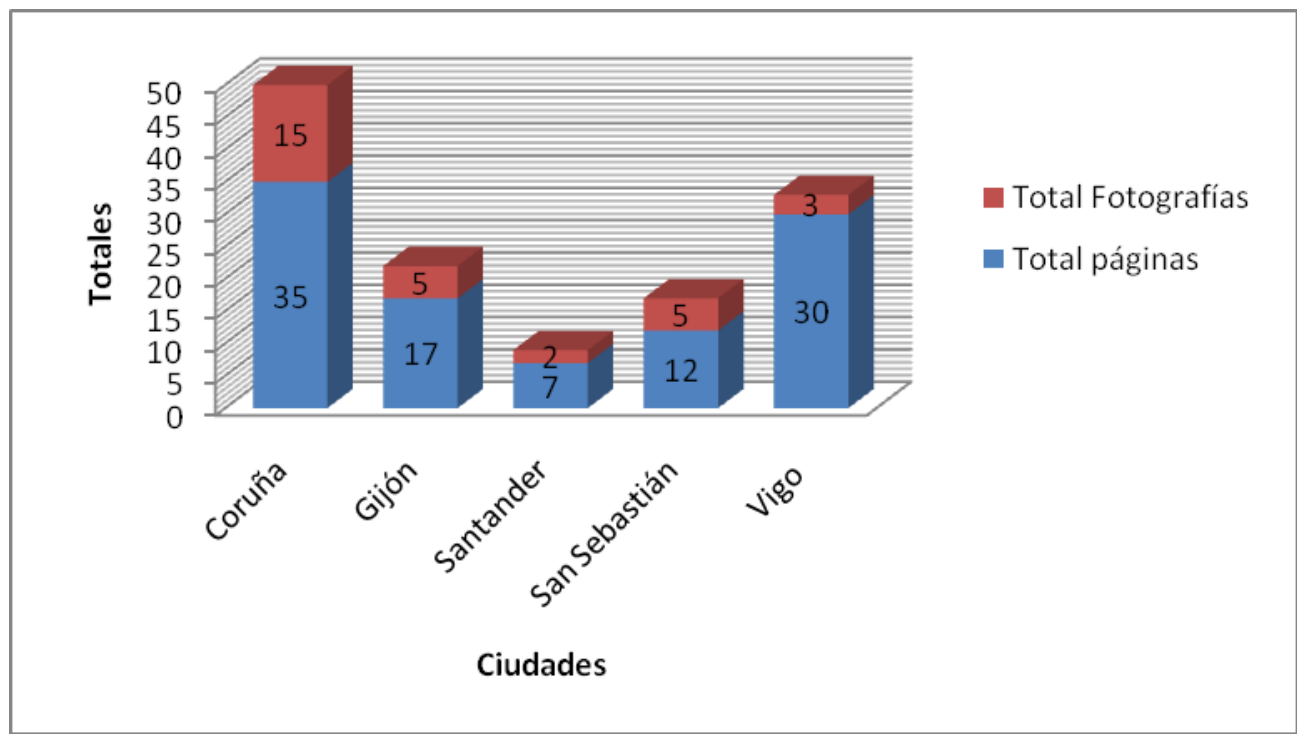

Fuente: elaboración propia

\section{$>\quad$ Número de amigos que estas ciudades poseen según el carácter de las páginas de Facebook.}

Al establecer un análisis conjunto, que recoge los datos de todas las ciudades, comprobamos que la ciudad que más adeptos consigue en Facebook es A Coruña con un total de 107.486 personas. En segunda posición se encuentra Vigo, aunque con un número mucho menor 52.630. A esta le siguen las siguientes ciudades: Gijón (48197), San Sebastián (31.039) y Santander (30.451). 


\section{$>\quad$ Carácter de las páginas más utilizadas, ante la búsqueda de estas ciudades en Facebook.}

En la segunda gráfica comprobamos que A Coruña vuelve a destacar en cuanto a número de páginas se refiere, con un total de 35 páginas de las cuales, hemos de recordar, que las dedicadas al tema plataforma eran las principales, muy seguidamente de las de turismo. Además el resto de clasificación vuelve a ser la misma que en el apartado anterior, Vigo (30), Gijón (17), San Sebastián (12) y finalmente Santander con 7.

\section{$>\quad$ Tipo de páginas que recogen un mayor número de fotografías de estas ciudades en Facebook.}

En último lugar analizamos las páginas que recogen fotografías que ilustran a las ciudades analizadas. En este caso A Coruña vuelve a estar a la cabeza de la clasificación con 15 páginas que incluyen fotografías de la ciudad. Seguidamente encontramos que dos ciudades tienen la misma puntuación: Gijón y San Sebastián poseen 5 páginas con imágenes de sus ciudades y finalmente, se sitúa Vigo con 3 Santander con 2.

\section{Comparación de resultados general}

Gráfico No 18 


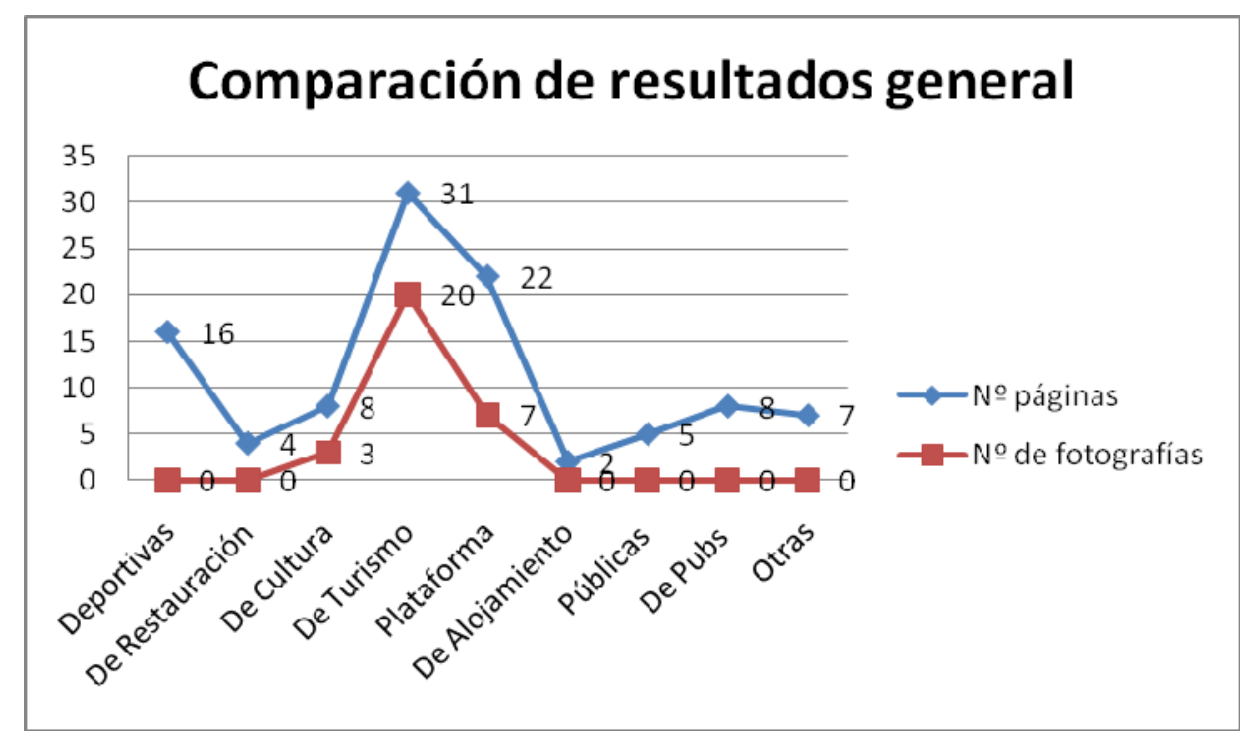

Fuente: elaboración propia

Gracias a esta tabla podemos observar de forma clara que el tema principal de las páginas más utilizadas es el turismo. A este tema le siguen las páginas plataformas y las deportivas. Es de destacar el número de páginas de Pubs, que en su gran mayoría pertenecen a la ciudad de Vigo.

En el caso del número de fotografías, comprobamos que el turismo vuelve a ser, con diferencia, el tema de las páginas que más imágenes muestra de sus respectivas ciudades. A este le siguen las páginas de cultura y las plataforma. Observamos como el resto de temas de las páginas, no poseen fotografías de sus ciudades.

Gráfico No 19 


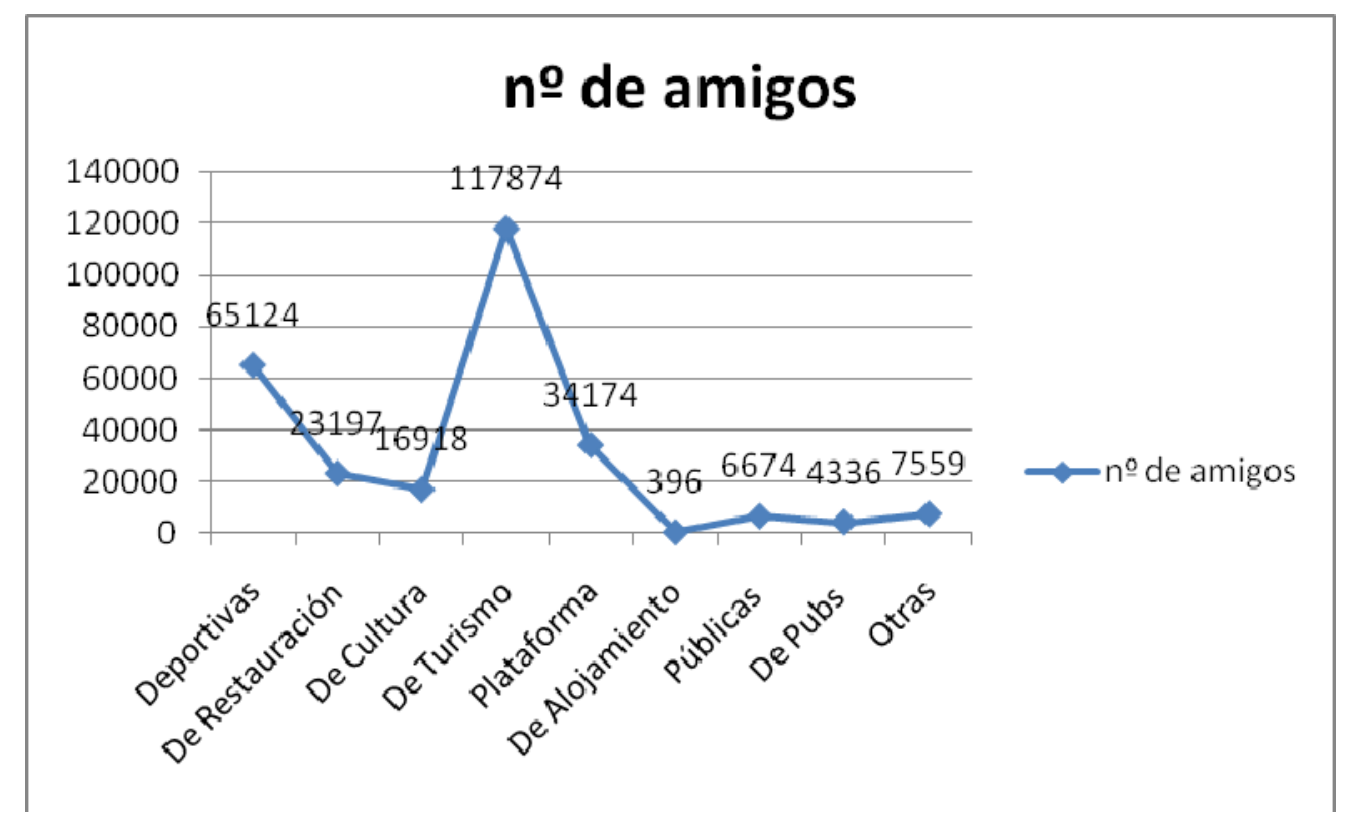

Fuente: elaboración propia

En cuanto al número de amigos, las páginas de turismo vuelven a estar en la primera posición del ranking (117874), situándose muy por encima de su principal competidor, como son las páginas de deportes (65124). En estas páginas deportivas, el deporte por excelencia es el futbol, que como vemos atrae a miles de seguidores. Las páginas plataforma también están bien posicionadas, después de las deportivas. Finalmente comprobamos que las que menos éxito tienen en la red son las de alojamiento, las públicas, pubs y otras.

\section{Resultados del turismo en Facebook}

Gráfico No 20 


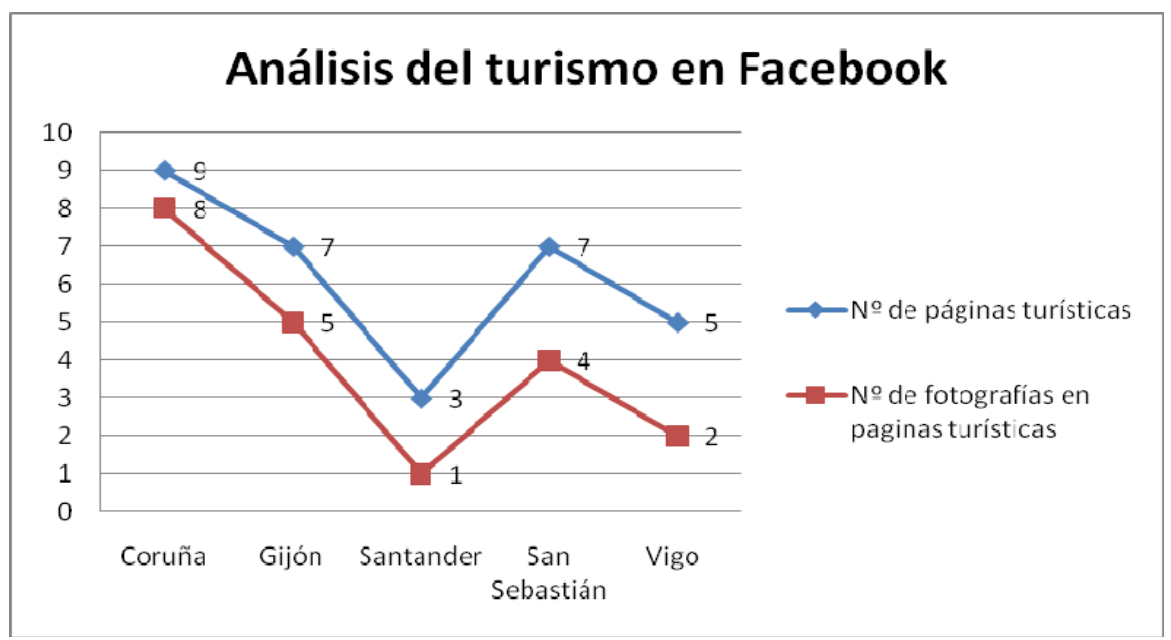

Fuente: elaboración propia

Tras la información de las últimas gráficas y al comprobar la importancia del turismo en la red, hemos decidido analizar de forma más pormenorizada todos los datos posibles del turismo en Facebook, según las distintas ciudades. Así, descubrimos que A Coruña es la ciudad con un mayor número de páginas dedicadas al turismo y además, es la que recoge un mayor número de fotografías en las páginas de carácter turístico. En cuanto a número de páginas se refiere, en segunda posición encontramos dos ciudades con la misma puntuación, Gijón y San Sebastián. Nos sorprende, principalmente el escaso número de páginas turísticas y de número de fotografías de la ciudad de Santander.

Gráfico No 21 


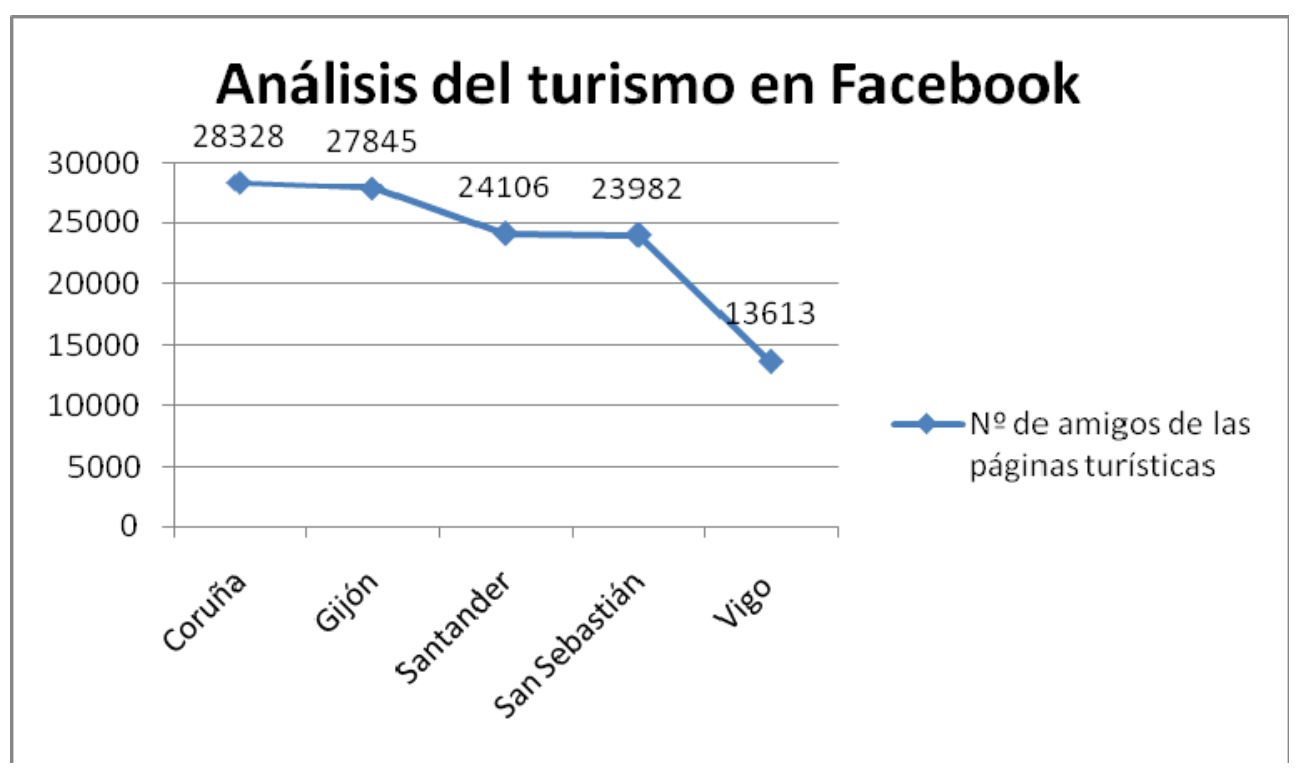

Fuente: elaboración propia

En cuanto al número de amigos, A Coruña vuelve a ocupar la primera posición con un total de 28328 personas, a las que les gustan las páginas de turismo de A Coruña. A esta ciudad le sigue muy de cerca Gijón con 27845 amigos y Santander con 24106. En general las páginas turísticas de cualquiera de las ciudades poseen un número elevado de adeptos.

\section{Resultados de la encuesta}

La encuesta se ha llevado a cabo con el propósito de averiguar la presencia de A Coruña en Facebook. Para ello se han realizado 6 preguntas, cada una con una puntuación del 1 al 7 , donde 1 es la puntuación más baja y 7 la más alta. En la última pregunta, sin embargo, consistía en elegir uno de los elementos que se presentaba como respuesta.

Los resultados finales que hemos extraído, son los siguientes:

1. En A Coruña existen actividades y atracciones culturales de mucho interés (monumentos históricos, eventos, festividades populares, conciertos, etc.)

1| $1.19 \%$ (1 votos) 
2l $2.38 \%$ (2 votos)

$3 \quad 11.90 \%$ (10 votos)

$4 \quad 9.52 \%$ (8 votos)

$5 \quad 42.86 \%$ (36 votos)

$6 \quad 17.86 \%$ (15 votos)

$7 \quad 14.29 \%$ (12 votos)

2. A Coruña es una ciudad cuyos habitantes son hospitalarios y amables.

$1 \quad 8.33 \%$ (7 votos)

$29.52 \%$ (8 votos)

$3 \quad 11.90 \%$ (10 votos)

$4 \quad 13.10 \%$ (11 votos)

$5 \quad 22.62 \%$ (19 votos)

$6 \quad 25.00 \%$ (21 votos)

$7 \quad 9.52 \%$ (8 votos)

3. A Coruña es una ciudad que respeta el medio ambiente.

1) $2.38 \%$ (2 votos)

2. $3.57 \%$ (3 votos)

$3 \quad 13.10 \%$ (11 votos)

$4 \quad 30.95 \%$ (26 votos)

$5 \quad 38.10 \%$ (32 votos)

$6 \quad 9.52 \%$ (8 votos)

7| $2.38 \%$ (2 votos)

4. A Coruña es una ciudad moderna y que destaca por el uso de las nuevas tecnologías.

1) $2.38 \%$ (2 votos)

$24.76 \%$ (4 votos)

$3 \quad 16.67 \%$ (14 votos)

$4 \quad 33.33 \%$ (28 votos)

$5 \quad 25.00 \%$ (21 votos) 
$6 \quad 14.29 \%$ (12 votos)

$7.5 .57 \%$ (3 votos)

5. Con la apertura de mi perfil en Facebook estoy mejor informado/a de las oportunidades que presenta A Coruña.

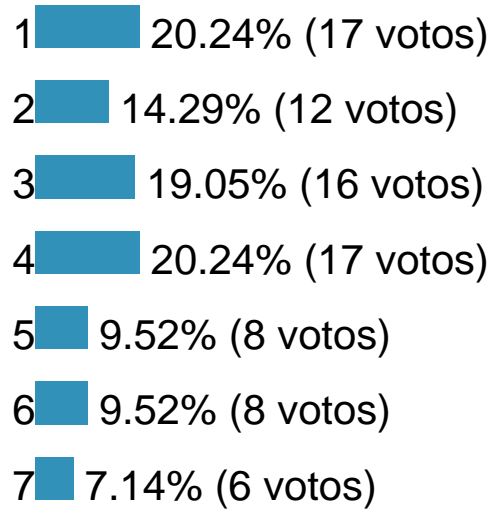

6. ¿Con cuál de los siguientes elementos identifica mejor A Coruña?

La Torre de Hércules 67.86\% (57 votos)

El Real Club Deportivo de A Coruña 14.29\% (12 votos)

La vida nocturnal 1.19\% (1 votos)

Las compras (Centros Comerciales) 10.71\% (9 votos)

La gastronomía | 1.19\% (1 votos)

Las playas $3.57 \%$ (3 votos)

Los museos | 1.19\% (1 votos)

Han contestado a la presente encuesta, a través de Facebook, un total de 84 personas. Sabemos que, para que el resultado de una encuesta sea correcto debe recoger un número mayor de contestaciones, pero en nuestro caso, la propia aplicación que nos facilitaba la encuesta originó problemas durante el tiempo que esta estuvo activa. Además, uno de los motivos de la realización de la encuesta era comprobar la efectividad de las nuevas aplicaciones que ofrece Facebook, como un tipo diferente de herramienta de recogida de datos para este tipo de estudios.

Aún así, de estos 84 resultados podemos extraer las siguientes conclusiones: 
1. La mayoría de los encuestados (una suma de 63 personas) consideran que en A Coruña existen atractivos de gran interés cultural, con una votación media de entre 5 y 7 . Este es un dato positivo para el turismo de la ciudad, donde la mayoría ven en A Coruña un lugar que les permite asistir a lugares, eventos o actuaciones interesantes.

2. En cuanto a la hospitalidad de los coruñeses, las votaciones están muy repartidas. La mayoría aportan una puntuación entre el 5 y 6 , pero también es de destacar el alto número de votos que han recibido las puntuaciones más bajas. Por ello, en este caso, consideramos que la amabilidad de los coruñeses no está del todo clara en la red social de Facebook.

3. Un total de 32 personas, que simbolizan en esta pregunta la mayoría, consideran, con una puntuación de 5 que A Coruña es una ciudad que respeta el medio ambiente. La siguiente respuesta más votada es 4. Por lo tanto, creemos que la ciudad todavía no está posicionada como un destino suficientemente "verde", pero tampoco creemos que muestre una imagen de contaminación y degradación del medio ambiente.

4. En esta pregunta, comprobamos que A Coruña no está posicionada, por el momento como una ciudad cosmopolita y moderna, puesto que la mayor puntuación es un 4. Aunque, también es cierto que los datos tampoco son desfavorables, son principalmente neutrales.

5. En este caso existe un empate entre dos respuestas, las que muestran una puntuación de 1 y de 4 en las más votadas. Por ello consideramos, que por el momento, en Facebook no se están desarrollando las medidas adecuadas de promoción de la ciudad, puesto que los datos de la encuesta afirman que tras la apertura de un perfil en Facebook no se está mejor informado de las oportunidades de A Coruña.

6. Finalmente, la última pregunta nos apunta que la Torre de Hércules, es el elemento, que con diferencia, identifica mejor a la ciudad (57 votos). A este le sigue el Deportivo de la Coruña (12) y las Compras (8). Sorprende la baja posición de los museos, donde solamente una persona los eligió en su contestación.

Por todo ello consideramos que A Coruña ofrece una imagen regular en Facebook, que se podría definir como aceptable, puesto que su puntuación no 
sobresale en ninguna de las respuestas. Esto puede ser debido a la poca incidencia de la promoción del destino en Facebook.

\section{Conclusiones}

Después del análisis de los anteriores resultados, extraemos las siguientes conclusiones:

\section{El papel que ocupa el turismo en Facebook.}

D El turismo es el elemento que tiene una mayor presencia en Facebook, en las tres modalidades analizadas (número de páginas, número de amigos y número de páginas con fotografías de las ciudades) y para las cinco ciudades estudiadas.

\section{Presencia de A Coruña en Facebook.}

$>\quad$ Al establecer un análisis conjunto, que recoge los datos de todas las ciudades, comprobamos que la ciudad que más adeptos consigue en Facebook es A Coruña con un total de 107.486 personas. En segunda posición se encuentra Vigo, aunque con un número mucho menor 52.630. A esta le siguen las siguientes ciudades: Gijón (48197), San Sebastián (31.039) y Santander (30.451).

> A Coruña es, sin lugar a dudas, (dentro de las ciudades analizadas), la ciudad que posee tanto en las páginas, número de amigos, y fotografías de las ciudades, una mayor presencia turística.

$>$ En el análisis pormenorizado de A Coruña extraemos la siguiente información: El mayor número de páginas son las dedicadas a "plataforma", sin embargo el mayor número de amigos se encuentran en las páginas de turismo, y también es en esta última donde encontramos un mayor número de fotografías de la ciudad. En relación a las fotografías podemos añadir que la mayoría muestran imágenes aéreas de A Coruña y de sus playas y calles.

En general, todos los comentarios que existen en las páginas de $A$ Coruña, son positivos, resaltando y defendiendo a la ciudad. Sin embargo, los comentarios negativos que más se repiten son: la lluvia y el mal tiempo y por otro lado las playas y su continuo relleno de arena. 


\section{Situación de Gijón, Santander, San Sebastián y Vigo en Facebook.}

> Dentro del caso de Gijón las páginas dedicadas a turismo son, con gran diferencia, las que más se repiten. Además, analizando más detalladamente el caso de las páginas turísticas vemos que estas son más especializadas que las páginas de A Coruña.

Santander presenta un aspecto negativo en cuanto al nombre se refiere, por la confusión en Facebook con el Santander de Colombia. Este aspecto negativo puede convertirse en positivo si tenemos en cuenta que puede llegar a un número mayor de personas al aparecer en la búsqueda del Santander de Colombia.

$>\quad$ De la ciudad de San Sebastián destacamos dos aspectos: por un lado la realización de varias de sus páginas paginas por turistas extranjeros (lo que ofrece una imagen de importancia e interés por la ciudad) y por otro lado la ausencia de páginas deportivas. Con este último dato comprobamos la importancia de los equipos locales y la afición de los mismos.

> Sorprende en el caso de Vigo el elevado número de páginas de Pubs, aunque bien es cierto que esta ciudad posee una actividad nocturna destacable. Al analizar el número de amigos comprobamos que las páginas deportivas se sitúan a la cabeza, gracias en este caso al Celta de Vigo.

\section{Opinión de los usuarios de Facebook a cerca de A Coruña.}

Ante los resultados de la encuesta consideramos que A Coruña ofrece una imagen regular en Facebook, que se podría definir como aceptable, puesto que su puntuación no sobresale en ninguna de las respuestas. Aún así podemos extraer dos resultados clave para la investigación:

El primero de ellos hace referencia a la mala promoción de A Coruña en Facebook, puesto que los resultados muestran que los encuestados no están mejor informados sobre A Coruña tras la creación de su perfil en Facebook.

El siguiente resultado a destacar es la votación aplastante de la Torre de Hércules como elemento representativo de la ciudad.

$>\quad$ En general, y teniendo en cuenta la importancia que para los turistas supone internet (recordemos que son los que efectúan un mayor número de 
búsquedas en internet) la promoción de las ciudades en estos medios, es por el momento deficiente y debe de ser mejorada con el tiempo.

\section{BIBLIOGRAFÍA:}

Castells, M. (2009), La Sociedad Red. Alianza editorial, Madrid.

Celeya, J. (2008), La Empresa En La Web 2.0. Gestión 2000.Barcelona.

Christakis, A. N. Fowler, H.J.(2010) Conectados. Taurus, 2010. Madrid.

Annan, Kofi. Discurso inaugural. WSIS 2003. Ginebra.

Castaño, C. (2008) La Segunda Brecha Digital. Catedra Ediciones. Madrid.

Colbert, F. Cuadrado, M. (2009) Marketing De Las Artes y La Cultura. Ariel. Barcelona.

Del Barrio, S. G. Predictores Del Interés Hacia La Información Sobre Promociones De Ventas En Internet. Tesis doctoral, Granada. Universidad de Granada, 2009.

Fages, R. (2008) Actitud 2.0 La Política Más allá De Los Blogs. $<$ http://www.uoc.edu/idp/7/dt/esp/fages.pdf $>$.

González, A. F. (2009) Congreso Turitec. Madrid.

Instituto politécnico nacional.Web. Instituto politécnico nacional.<http://www.dcyc.ipn.mx/dcyc/quesonlastics.aspx>.

Larrañaga, J. Ruiz, A. (2009) El Modelo De Negocio De YouTube. <http://www.scribd.com/doc/16917537/Icono14-N-12-EL-MODELO-DENEGOCIO-DE-YOUTUBE>.

Monsoriu, M. F (2008). Manual De Redes Sociales En Internet. Creaciones Copyright. Madrid.

Petrizzo, M. REDES. Revista hispana para el análisis de redes sociales. $<$ http://revista-redes.rediris.es>.

Pisani, F (2008). Periodismo digital. Taller. Tecnológico de Monterrey, Campus Ciudad de México.

Pita Fernández, S. Pértegas Díaz, S. "Investigación cualitativa y cuantitativa." 2002.<http://www.laalamedilla.org/Webpracticas/cd/documentos/cuanti c uali2.pdf>.

Requena, F. (1989) El Concepto De Red Social. Madrid. 
Ricaurte, P. Ortega, E. (2009)"Facebook o Los Nuevos Rostros De La Sociedad."<http://www.alaic.net/alaic30/ponencias/cartas/Internet/ponen cias/GT18 35Ricarte Ortega.pdf>

Rivera, J. C y De Juan D.V. (2002). La Promoción De Ventas. Esic. Madrid.

Segura, M. (2009) Panorama Internacional De Las TIC En La Educación. Barreras Actuales $y$ Propuestas De Futuro. http://sociedadinformacion.fundacion.telefonica.com/telos/articulocuader no.asp@idarticulo=3\&rev=78.htm

Serrano, A. Martinez, E. (2003) La Brecha Digital, Mitos y Realidades. Universidad autónoma de Baja California.

Zorita, E. L. (2000)Marketing Promocional. ESIC. Madrid.

Páginas Web:

Facebook: www.facebook.com

MySpace: www.myspace.com

Tuenti: www.tuenti.com

Hi5: www.hi5.com

Youtube: www.youtube.com

LinkedIn: www.linkedin.com

Xing: www.xing.com

Minube: www.minube.com

Tripadvisor: www.tripadvisor.com

Toprural: www.toprural.com

Identidad Legítima: http://identidadlegitima.com/

Terra noticias: www.terranoticias.com

El país.com: www.elpais.com

Diccionario de la lengua española: www.rae.es

Revista control de publicidad: http://www.interactivadigital.com/

AIMC: www.aimc.com

Vídeo:

Tertulia Hosteltur 01/04/2010. Youtube.

Para citar este artículo:

Sánchez Amboage, Eva (17-12-2010). PROMOCIÓN DE UN DESTINO TURÍSTICO A TRAVÉS DE LAS REDES SOCIALES: EL CASO DE A CORUÑA EN FACEBOOK. REDMARKA - CIECID - Unidad de Investigación en Marketing Aplicado-Universidad de A Coruña Año II, Número 5, V1, pp.11-52 ISSN 1852-2300 URL del Documento : cienciared.com.ar/ra/doc.php?n=1412 